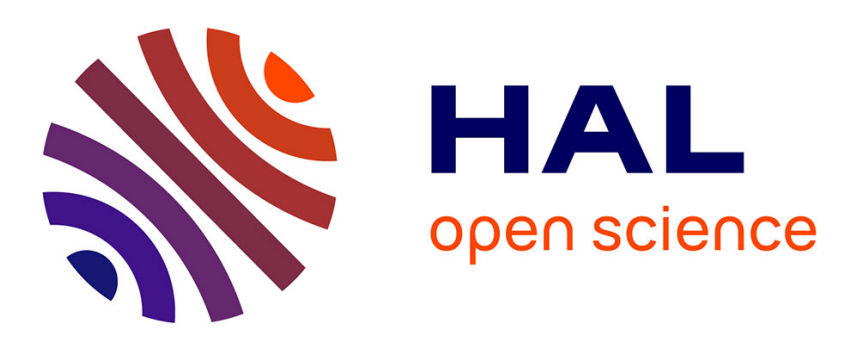

\title{
Quantitative Easing, Credibility and the Time-Varying Dynamics of the Term Structure of Interest rate in Japan
}

\author{
Yusho Kagraoka, Zakaria Moussa
}

\section{To cite this version:}

Yusho Kagraoka, Zakaria Moussa. Quantitative Easing, Credibility and the Time-Varying Dynamics of the Term Structure of Interest rate in Japan. 2010. halshs-00543010

\section{HAL Id: halshs-00543010 \\ https://shs.hal.science/halshs-00543010}

Preprint submitted on 5 Dec 2010

HAL is a multi-disciplinary open access archive for the deposit and dissemination of scientific research documents, whether they are published or not. The documents may come from teaching and research institutions in France or abroad, or from public or private research centers.
L'archive ouverte pluridisciplinaire HAL, est destinée au dépôt et à la diffusion de documents scientifiques de niveau recherche, publiés ou non, émanant des établissements d'enseignement et de recherche français ou étrangers, des laboratoires publics ou privés. 


\section{GREQAM}

Groupement de Recherche en Economie Quantitative d'Aix-Marseille - UMR-CNRS 6579

Ecole des Hautes études en Sciences Sociales Universités d'Aix-Marseille II et III
Document de Travail $n^{\circ} 2010-49$

Quantitative Easing, Credibility and the Time-Varying Dynamics of the Term Structure of Interest rate in Japan

\section{Yusho Kagraoka}

Zakaria Moussa

December 2010 


\title{
Quantitative Easing, Credibility and the Time-Varying Dynamics of the Term Structure of Interest rate in Japan
}

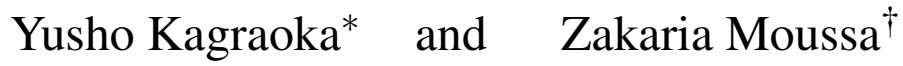

October 2010

\begin{abstract}
A key issue in current research about quantitative easing monetary policy (QEMP) is the ability of this strategy to impact the term structure of interest rates. Using a dynamic model for the yield curve with time-varying-parameters to the Japanese data, we provide three insights. First, the expectations hypothesis of the term structure of interest rates is generally supported even during the QEMP period. Second, the estimation results reveal that the contribution of macroeconomic variables on the variation of the yield curve is relatively small, especially during the QEMP period. As for the feed-back effect, the yield curve factors contribute only marginally to inflation variation. However, they account for more relevant part of output gap dynamics. Third, the monetary policy shock has a significant effect on yield curve level factor only during the high interest rates periods. However, the decline in the level factor during the QEMP period, while insignificant, indicates a strengthening credibility of the Bank of Japan and thus the effectiveness of its policy.
\end{abstract}

JEL Classification : C32; E52

Keywords: Quantitative Easing Policy; Macro-finance model; Time-varying-parameter VAR; Japan; Expectation channel

*Musashi University, 1-26-1 Toyotama-kami, Nerima-ku, Tokyo 176-8534, Japan. kagraoka@cc.musashi.ac.jp

†Université de la Méditerranée and GREQAM, Centre de la Vieille Charité, 2 rue de la Charité, 13002 Marseille, France. zakaria.moussa@univmed.fr 


\section{Introduction}

In a zero interest rate environment the short-term interest rate is no longer a policy instrument under the direct control of the central bank. The alternative monetary policy used by most major central banks is monetary easing. The goal of the central bank is therefore to impact the economy across the yield curve, bringing down long-term interest rates, thereby boosting the economy. The aim of this paper is to examine the effectiveness of such a policy in affecting the yield curve using the Japanese experience of QEMP. We are particularly interested in analyzing the possible bi-directional feedback from the yield curve to the economy.

The QEMP as implemented by the BOJ comprised three courses of action namely, (i) injecting ample liquidity into the market using the current account balances $(\mathrm{CAB})$ as the main monetary policy instrument, (ii) making a commitment to maintain short-term rates at around zero until the CPI inflation stabilized at zero percent or increased year after year and (iii) purchasing more of long-term Japanese government bonds (JGBs). The transmission mechanisms suggested by this policy are the portfolio-rebalancing channel (Metzler (1995)) and the expectation channel which consists of the policy-duration effect (Krugman (2000) and Eggertsson and Woodford (2003)) and the signaling effect.

This paper evaluates the effectiveness of the QEMP, focusing on the expectation channel. The effectiveness of such a channel depends totally on the credibility of the central bank's policy of maintaining the future short-term interest rate at a near zero level. The desired intermediate effect of the monetary policy is that the reduction of expected future short-term rates will be transmitted to the long end of the yield curve. The decline in the long-term interest rates will, in turn, lead to increased expectations of inflation and stimulate activity.

Several papers have examined the effectiveness of this transmission channel by focusing on the term structure of interest rates. Oda and Ueda (2007), Okina and Shiratsuka (2004) and Baba et al. (2005) show that policy duration has a clear and significant effect, lowering the yield curve. The common point of these papers is that they do not examine the transmission of this positive effect to the real economy. On the other hand, Evans and Marshall (2007) and Ang and Piazzesi (2003) examine the joint dynamics of bond yields and macroeconomic variables in a vector autoregression. Ang and Piazzesi (2003) show that a substantial portion of short- and medium-term bond yields is explained by macroeconomic variables. In contrast, Evans and Marshall (2007) find that macroeconomic variables do also explain much of the long-term bond yield dynamics. For the Japanese case, Nakajima et al. (2010), using a timevarying-parameter VAR model (TVP-VAR), show some evidence of the effectiveness of policy duration in lowering five-year JGB yields, although this effect is not transmitted to the real economy. One potential drawback of such models is that few specific yields are taken into consideration. The results may therefore not reflect to full range of term structure. Diebold 
et al. (2006) examine the interactions between the macroeconomy and the yield curve by means of the one-step Kalman filter approach. They aggregate information from a large set of yields using latent factors, which represent the level, the slope and the curvature, based on Nelson and Siegel (1987)'s model. Using this model, which allows for correlated latent yield factors and observed macroeconomic variables, Diebold et al. (2006) show that macroeconomic variables have strong effects on future movements of the yield curve, while latent interest rate factors have a relatively small impact on macroeconomic variables.

Needless to say, it could be unrealistic to assume time-invariance either in monetary policy transmission mechanisms or in the structure of the Japanese economy. Indeed, as already documented in several papers for the Japanese economy (Miyao (2000), Fujiwara (2006), Inoue and Okimoto (2008), Nakajima et al. (2009) and Girardin and Moussa (2010)), there is clear evidence of significant structural changes in the last two decades. As shown in Cargill et al. (2001), the Japanese economy has become very unstable having experienced significant institutional and monetary strategy changes during the "lost" decade. For these reasons and for the first time to the best of our knowledge, we employ a generalized Nelson-Siegel model with time-varying coefficient and stochastic volatilities, as described in Bianchi et al. (2009), for the Japanese case. This study differs from previous studies on the JGB market on three points. Firstly, it focuses on a more complete set of possible macroeconomic variables and monetary policy instruments and their possible effects on the term structure of interest rates. Secondly, it allows us to take into account potential instabilities both in monetary policy transmission mechanisms and in the relationship between yield curve and the structure of the economy. Finally, the data sample in this study is significantly larger; data span the period between February 1985 and October 2009. This allows us to analyze the relationship between yield curve and macroeconomic and monetary variables under different economic conditions, i.e. periods with different monetary policy strategies.

The objective of this work is twofold. First, we propose a constrained smoothing Bsplines method to estimate the yield curve of zero-coupon bonds using JGB prices. Given that short term interest rates were even lower than usual during the QEMP period, using traditional yield curve models could result in negative values for yields with short maturity during this period. In order to overcome this problem we incorporate non-negative restrictions in the smoothing B-splines method. Second, we apply a time-varying parameter macro-finance model to data on JGBs with 17 different maturities as well as three macroeconomic variables, namely, output gap, inflation and monetary policy instrument.

Contrary to the results of standard term-structure models with time-invariant term premia, our results show that the expectations hypothesis of the term structure of interest rates is generally supported even during the QEMP period. This is a necessary condition for the effectiveness of the expectation channel. Moreover, the estimation results reveal that the contribution 
of macroeconomic variables to the yield curve variation is relatively small, especially during the QEMP period. As for the feed-back effect, the yield curve factors contribute only marginally to inflation variation. They account for a greater part of output gap dynamics during the period of high interest rates, but these effects revert to a much lower level during the QEMP period. These results indicate that during the deflationary period and under the zero lower bound of interest rates the relationship between financial markets and macroeconomic variables becomes very weak. These findings are corroborated by the impulse response functions. The monetary policy shock has a significant effect on the yield curve level factor only during the high interest rate periods. However, during the QEMP period the decline in the level factor, while insignificant, indicates strengthening credibility of the BOJ and thus the effectiveness of its policy.

The rest of the paper is structured as follows. The next section presents the term structure estimation and the data construction. Section 3 describes the time-varying parameter macroyield model. The results are presented in section 4 and finally section 5 concludes.

\section{Estimating zero-coupon yield curves for Japan}

\subsection{Data construction}

We base our analysis on data originating from two different sources and covering the period from 1985:02 to 2009:10. Data were provided by Tokyo Stock Exchange (TSE) and Japan Securities Dealers Association (JSDA) ${ }_{1}^{1}$. The data set comprises beginning-of-month observations of the officially quoted prices, remaining maturities and coupons of a total of 374 listed public debt securities. The data used for estimating zero coupon yield curves cover three categories of government issues: 10-year JGB 2 , 3-month treasury bills (3m TB) and 3-month financing bills ${ }^{3}(3 \mathrm{~m}$ FB). In order to obtain a more homogeneous set of data, TB and FB prices are adjusted for withholding tax which is levied at issuance and repaid at redemption ${ }^{4}$. The number of debt securities available for each month varies considerably until the end of 2000, between 48 and 89 and it grows sharply from 2001 to vary only between 86 and 95 . In order to select the most accurately priced bonds, we apply several data filters. We eliminate the data for 10-year JGBs with remaining maturity of less than half a year not only because of the ex-

\footnotetext{
${ }^{1}$ From 1985:02 to 2001:12 data are provided by TSE while from 2002:01 to 2009:10 data are provided by JSDA.

${ }^{2}$ The 10-year JGBs are most liquid bonds in the Japanese bond market, and they work as benchmarks for bond investors.

${ }^{3}$ The issue of 3-month TB was terminated in 2000:03 while maturity of financing bills (FB) is extended to three months in 1999:04. As for three-month yield, we treat therefore 3-month TB and 3-month FB interchangeably.

${ }^{4}$ Prices are adjusted according to this formula: $P_{a d j}=\frac{P \cdot F}{F+\left(F-P_{0}\right) \cdot t}$, where P represents the market price, $P_{a d j}$ the tax-adjusted market price, $\mathrm{F}$ the face value, $P_{0}$ issue price and $t$ the tax rate $(0.18)$.
} 
istence of a redemption fee 5 but also because these JGBs are not actively traded and appear to be significantly influenced by their low liquidity and therefore they are not accurately priced. Moreover, in order not to distort "real" yields we eliminate outliers from data set bonds. We exclude then bonds whose yields differ greatly from these at nearby (similar) maturities.

\subsection{Estimation procedure}

Our objective is to estimate macro-dynamic yield model using the zero-coupon yields. In order to estimate the zero-coupon yield curve, given a set of bond prices, we apply the B-spline method and parametrize the zero-coupon yield curve in terms of a cubic B-spline. Moreover, we apply smoothing splines that incorporate a roughness penalty parameter, as the Bank of Japan approach and use Fisher et al. (1995) method to estimate zero-coupon yield curve. The advantage of using this method is that the cubic B-spline has base functions which have compact support (non-zero function value) in a knot interval, and we can impose non-negative zerocoupon yield restriction in the estimation procedure. This is even more important when using Japanese data since, in the special case of the zero-interest-rate environment characterizing the Japanese economy since 1999, short maturity bond yields can be negative 6 .

Given the wealth of literature detailing the use of smoothing cubic spline to extract zerocoupon yields, we provide only the essential elements of the method 7 . Consider a set of $\mathrm{N}$ bonds traded on one date. Let $P_{i}$ be the market price of bond $i,\left\{C_{i, j}\right\}_{1 \leq j \leq k_{i}}$ be its principal and interest payment, which is paid at a set of cash flow dates $\left\{t_{i, j}\right\}_{1 \leq j \leq k_{i}}$. Under the classical assumptions that there is no taxes or transaction costs, absence of arbitrage implies that the observed bond price (market price plus accrued interest $a_{i}$ ) is equal to the present value of its future cashflows:

$$
\begin{aligned}
P_{i}^{o b s}=P_{i}+a_{i}=\hat{P}_{i}+\varepsilon_{i} & =\sum_{j=1}^{k_{i}} C_{i, j} \delta\left(t_{i, j}\right)+\varepsilon_{i} \\
& =\sum_{j=1}^{k_{i}} C_{i, j} \exp \left(-t_{i, j} \zeta\left(\tau_{i, j}\right)\right)+\varepsilon_{i} \\
& =\sum_{j=1}^{k_{i}} C_{i, j} \exp \left(-\int_{0}^{t_{i, j}} f(s) d s\right)+\varepsilon_{i}
\end{aligned}
$$

\footnotetext{
${ }^{5}$ Bonds with a remaining time to maturity below half a year are usually excluded to estimate yield curves using Japanese government securities. This because the redemption fee could lead to negative yields. This issue doe not impose problem in our work since we impose positive spot rate constraint in estimation procedure, which is explained below.

${ }^{6}$ An other solution consists of replacing negative values of yields with zeros as in Ueno et al. (2006) that combine Black model with Gorovoi and Linetsky (2004) model to estimate yield curve where interest rates are considered as options and negative values are replaced by zeros.

${ }^{7}$ See Fisher et al. (1995) for more complete description of this model.
} 
where $\delta($.$) is the discount function, \varepsilon_{i}$ are independent and normally distributed with mean of zero and variance $\sigma^{2}$. It is widely known that the discount function $\delta(t)$ is related both to the spot rate $(\zeta(t))$ and to the instantaneous forward rate $(f(t))$ respectively by $\zeta(t)=-\ln (\delta(t)) / t$ and $f(t)=-\delta(t)^{\prime} / \delta(t)$.

When using the smoothed cubic B-spline we place the B-spline bases on the zero-coupon yield curve:

$$
\zeta(t)=\sum_{\tau=1}^{\kappa} \beta_{\tau} \phi_{\tau}(t)
$$

where $\phi(t)=\left(\phi_{1}(t), \phi_{2}(t) \ldots \phi_{\kappa}(t)\right)^{\prime}$ is a cubic B-spline basis, it is an $\kappa$-dimensional vector constructed from a set of basis functions $\left(\phi_{j}(t) ; j=1, \ldots, \kappa\right)$, and $\beta=\left(\beta_{1}, \ldots, \beta_{\kappa}\right)$ is an unknown parameter vector to be estimated and $\kappa$ is the number of knot points plus 2 . We impose positivity constraints in the estimation of the zero-coupon yield curve. Since the cubic B-spline basis functions take their maximum at a center of adjacent knot points, it suffices to verify positiveness of the zero-coupon yields at middle points of adjacent knot points so as to assure positive spot rates. Therefore, the zero-coupon yield curve is chosen to be the cubic B-spline which minimizes the objectif function for a given $\lambda$, with respect to $\beta$ as follows:

$$
\begin{gathered}
\stackrel{\operatorname{Min}}{\beta} \sum_{i=1}^{N}\left(P_{i}-\hat{P}_{i}(\beta)\right)^{2}+\lambda \int_{0}^{T} \zeta^{\prime \prime}(s) d s \\
\quad S C \quad \zeta(t) \geq 0(t \in[0, T])
\end{gathered}
$$

where $\mathrm{T}$ is the maximum maturity. The first term measures the error in the pricing of input bonds. The second term represents the roughness penalty parameter that sets the level of smoothing in term structure. It is the size of the roughness penalty parameter $(\lambda)$ that controls the tradeoff between the smoothness in the curve and the goodness of fit. The value of $\lambda$ is determined by Generalized Cross-Validation (GCV), it is chosen to minimize the expression

$$
\gamma(\lambda)=\frac{\sum_{i=1}^{N}\left(P_{i}-\hat{P}_{i}\left(\beta^{*}(\lambda)\right)\right)^{2}}{(N-\theta \operatorname{enp}(\lambda))^{2}}
$$

where $\operatorname{enp}(\lambda)$ is the effective number of parameters, $\theta$ the cost or tuning parameter. For each $\lambda$ we solve $\beta^{*}(\lambda)$ and then calculate $\gamma(\lambda)$. In this paper we impose non-negativity constraint when estimating $\beta$ to guarantee the positiveness of the zero-coupon yields 8 , otherwise the estimated zero-coupon yields may be negative at shorter maturities. In the Japanese case this problem could arise as short term interest rates are almost zero starting from 1999.

As for the number of knot points selected here, Fisher et al. (1995) suggest choosing the number of knot points to be roughly one third of the sample size. Applied to Japanese bond

\footnotetext{
${ }^{8}$ The estimates are made using Matlab software.
} 
market this gives us 15 knot points. It is also necessary to decide on their location; although the knots could be distributed evenly over time to maturity it is common to concentrate them towards the short end to capture the greater complexity of the curve at shorter maturities. The maturities at which our knots are located are 0, 0.25, 0.5, 0,75, 1, 2, 3, 4, 5, 6, 7, 8, 9 and 10 years. The size of the roughness penalty parameter $(\lambda)$ depends on that of the tuning parameter $\theta$, which is fixed by discretion. If this parameter was almost equal to zero there would be no smoothing of the curve and the resulting forward curve could oscillate wildly. Alternatively, if it was large, the estimated forward curve would be smoother at the expense of goodness of fit. We follow BIS (2005) and use a tuning parameter of 3.

\subsection{Summary statistics}

Figure 1 provides a composite picture of Japanese Government Zero-coupon yield curves over the sample period between 1985:02 and 2009:10. It shows that during the period of quantitative easing, from March 2001 to March 2006, yields for very short-term are zero. The non-negativity constraint prevents from possible negative yields for these years.

Figure 1. Japanese Government Bond yield curves 1985-2009

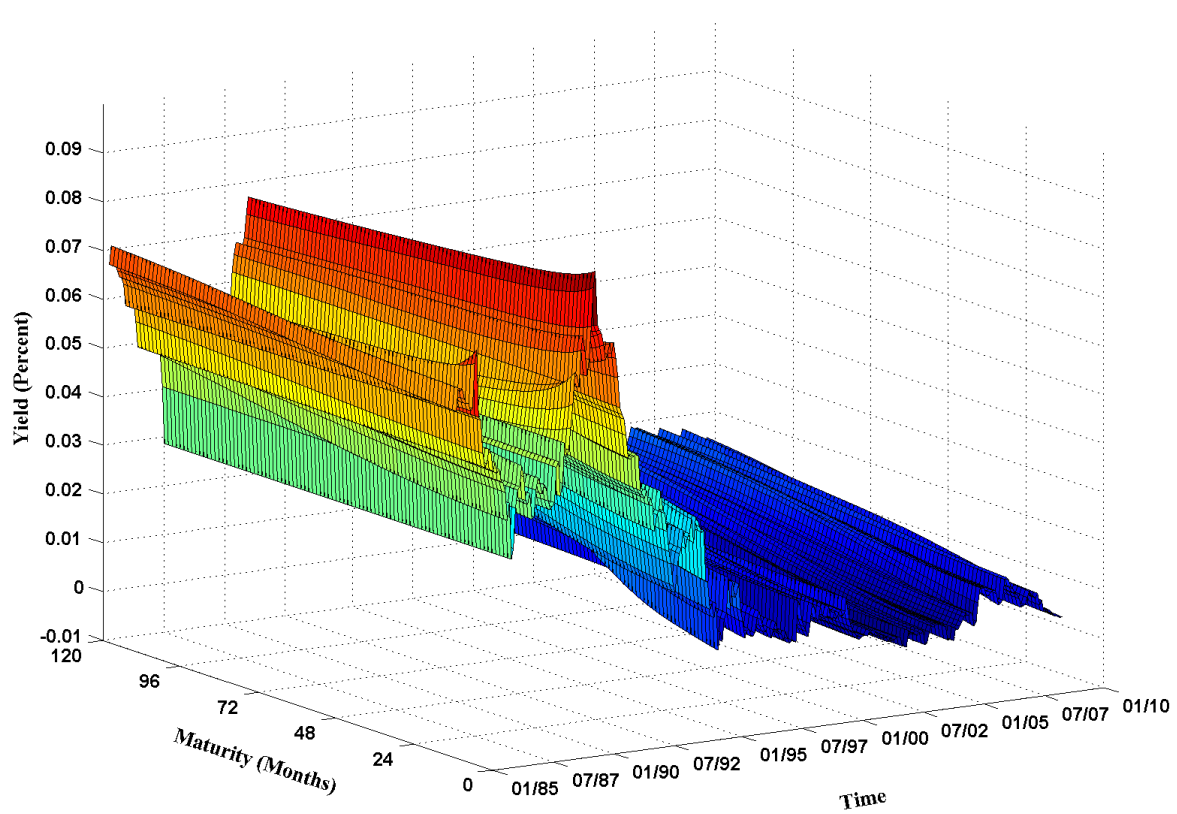

Note: zero-coupon yields are estimated using Fisher et al. (1995) model where we impose positive constraint. Sources: data on prices and bond specifications are provided by both TSE and JSDA.

In oder to summarize the statistical properties of the estimated zero-coupon yields over the sample period, we focus on the 1-, 5- and 10-year zero-coupon yields as representative 
short-, medium- and long-term interest rates. We define the level, the slope and the curvature as $\frac{1}{3}\left(y_{t}^{(12)}+y_{t}^{(60)}+y_{t}^{(120)}\right), y_{t}^{(12)}-y_{t}^{(120)}$ and $2 y_{t}^{(60)}-y_{t}^{(120)}-y_{t}^{(12)}$, respectively. Table 1 provides a summary of the descriptive statistics on the four measures of the zero-coupon yield curve. The downward level shift and the reduction in volatility of zero-coupon yields are apparent, especially at the long end of the curve. The average zero-coupon yield curve is upward sloping, meaning that zero-coupon yields rise as the maturity of bonds lengthens; standard deviations of zero-coupon yields generally decrease with maturity; and zero-coupon yields are highly autocorrelated, with decreasing autocorrelation at longer maturities. The zero-coupon yield levels show mild excess kurtosis at short maturities which decreases with maturity, and positive skewness at all maturities. Excess kurtosis is, however, more pronounced for first-differenced spot rates (for example, 4.145 for the 1-year spot rate). We reject the normality hypothesis at the 5\% level for all measures of the zero-coupon yield curve. These descriptive statistics are consistent with some stylized facts in bond pricing.

Table 1. Descriptive statistics: Japanese spot rate curves

\begin{tabular}{|c|c|c|c|c|c|c|c|c|c|}
\hline & & \multicolumn{5}{|c|}{ Central moments } & \multicolumn{3}{|c|}{ Autocorrelations } \\
\hline & & Mean & Std.Devn & Skewness & Kurtosis & J-B test & Lag 1 & Lag 2 & Lag 3 \\
\hline \multirow{5}{*}{$\begin{array}{l}\frac{n}{0} \\
\frac{0}{3} \\
\end{array}$} & 1-year & 0.0192 & 0.0193 & 1.5282 & 1.3529 & 0.000 & 0.9602 & 0.921 & 0.873 \\
\hline & 5-year & 0.039 & 0.024 & 0.964 & 0.333 & 0.000 & 0.968 & 0.94 & 0.907 \\
\hline & 10-year & 0.0507 & 0.0165 & 0.8649 & 0.2194 & 0.000 & 0.930 & 0.881 & 0.83 \\
\hline & Slope & -0.0315 & 0.0102 & 0.6199 & 0.4957 & 0.000 & 0.831 & 0.70 & 0.613 \\
\hline & Curvature & 0.0052 & 0.0098 & 0.9708 & 0.8497 & 0.000 & 0.853 & 0.778 & 0.71 \\
\hline \multirow{5}{*}{ 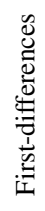 } & 1-year & -0.000339 & 0.003503 & -0.396 & 4.145 & 0.000 & -0.0161 & 0.228 & -0.171 \\
\hline & 5-year & -0.0004 & 0.0036 & 0.663 & 1.99 & 0.000 & -0.016 & -0.011 & -0.123 \\
\hline & 10-year & -0.000177 & 0.0059 & 0.333 & 2.861 & 0.000 & -0.1647 & -0.295 & -0.286 \\
\hline & Slope & -0.00016 & 0.0054 & 0.322 & 1.704 & 0.000 & -0.137 & -0.105 & 0.099 \\
\hline & Curvature & -0.00015 & 0.0051 & -0.927 & 5.407 & 0.000 & -0.26 & -0.126 & -0.034 \\
\hline
\end{tabular}

\section{Yield-Curve Fitting: The Macro-Finance Model}

\subsection{Methodology and Estimation}

The recent macro-finance literature has convincingly advocated the case for the existence of a bi-directional link between the term structure and the rest of the economy (Ang and Piazzesi (2003), Evans and Marshall (2007), Diebold et al. (2006) and Rudebusch and Wu (2008)). Moreover, as documented in several papers for the US and UK 9 , there is strong evidence of

\footnotetext{
${ }^{9}$ Prominent examples include Diebold et al. $(2006)$, Bianchi et al. $(2009)$, Rudebusch and Wu $(2008)$.
} 
instability in the dynamics of the yield curve. What makes the Japanese case particularly interesting is that its economy has become very unstable, having experienced significant institutional and monetary strategy changes during the "lost decade". However, even though earlier empirical contributions based on Japanese data (Oda and Ueda (2007), Okina and Shiratsuka (2004), Baba et al. (2005) and Ugai (2007)) show that macro variables have a clear and significant lowering effect on yield curve, they do not examine the potential reverse influence from the yield curve to the real economy. In addition, to the best of our knowledge no study has yet tried to model time variations in both the yield curve and the economy, simultaneously for the Japanese case.

The model presented here is proposed by Bianchi et al. (2009); it is set in state-space form and can be seen as a time-varying extension of the approach used by Diebold et al. (2006) and developed by Nelson and Siegel (1987). In particular, it allows for time variation in the state equation, thus revealing possible recurring structural breaks in the time series dimension of the underlying yield curve factors.

The observation equation is a description of the phenomenon that is being investigated. In the case of the Nelson-Siegel model, the observation equation would be the yield curve equation. The state equation is a description of how the underlying factors evolve over time; these factors are taken to be unobserved and will be estimated using the Kalman filter. The following equations represent the Nelson-Siegel model written in state-space form. First, the observation equation:

$$
y_{t}(\tau)=L_{t}+\left(\frac{1-e^{-\tau \lambda}}{\tau \lambda}\right) S_{t}+\left(\frac{1-e^{-\tau \lambda}}{\tau \lambda}-e^{-\tau \lambda}\right) C_{t}+e_{t}(\tau)
$$

where $y_{t}(\tau)$ is the bond yield to maturity $\tau$ at time $t ; L_{t}, S_{t}$ and $C_{t}$ are the unobservable level, slope and curvature factors of the yield curve, the factor loadings $1,\left(\frac{1-e^{-\tau \lambda}}{\tau \lambda}\right)$ and $\left(\frac{1-e^{-\tau \lambda}}{\tau \lambda}-e^{-\tau \lambda}\right)$ are for level, slope and curvature factors, respectively. The unity coefficient is a constant, so that it does not decay to zero in the limit. The loading of $S_{t}$ is an exponential function that starts at one and decays monotonically towards zero. The loading of $C_{t}$ starts at zero, increases with the maturity $\tau$ and then declines approaching zero. $\lambda$ is a parameter that governs the exponential decay and determines for which maturity the function assumes its maximum. We follow Diebold et al. (2006) ${ }^{10}$ and we set $\lambda$ equal to 0.0609. This implies that the curvature factor loading reaches its maximum at a maturity of 30 months. Following Bianchi et al. (2009) we assume that the idiosyncratic component $e_{t}(\tau)$ is serially correlated and heteroskedastic but uncorrelated across maturities $E\left(e_{t}(i)^{\prime} e_{t}(j)\right)=0$ for $i \neq j$. In particular: $e_{t}(\tau)=\rho(\tau) e_{t-1}(\tau)+\psi_{t}^{1 / 2}(\tau) \varepsilon_{t}$ where the volatility $\psi_{t}(\tau)$ follows a geometric random walk

\footnotetext{
${ }^{10}$ Diebold et al. (2006) choose $\tau=30$ months as a reference maturity for the "medium term" and set $\lambda$ equal to 0.0609 for US data.
} 
$\log \left(\psi_{t}\right)=\ln \left(\psi_{t-1}(\tau)\right)+\omega_{t}$. Second, the state equation describes the dynamics of these factors as a time-varying VAR:

$$
Z_{t}=\alpha_{t}+\sum_{p=1}^{P} \beta_{t, p} Z_{t-p}+v_{t}
$$

where the $n \times 1$ vector $Z_{t}=\left[L_{t}, S_{t}, C_{t}, \pi_{t}, Y_{t}, r_{t}\right]^{\prime}$ denotes macro and yields data matrix. The errors $v_{t}$ are assumed to be normally distributed with 0 mean and time-varying covariance matrix $\Omega_{t}$. Following Primiceri (2005) and Cogley et al. (2005), we use a triangular reduction of the state error covariance as follows:

$$
\Omega_{t}=A_{t}^{-1} \Sigma_{t} \Sigma_{t}^{\prime} A_{t}^{\prime-1}
$$

where $A_{t}$ is a lower triangular matrix with ones on the main diagonal and $\Sigma_{t}$ is a diagonal matrix. the time-varying matrices $\Sigma_{t}$ and $A_{t}$ are defined as follows:

$$
A_{t}=\left[\begin{array}{cccc}
1 & 0 & \cdots & 0 \\
a_{21, t} & 1 & \ddots & \vdots \\
\vdots & \cdots & \ddots & 0 \\
a_{n 1, t} & \ddots & a_{n(n-1), t} & 1
\end{array}\right] \text { and } \quad \Sigma_{t}=\left[\begin{array}{cccc}
\sigma_{1, t} & 0 & \cdots & 0 \\
0 & \sigma_{2, t} & \cdots & 0 \\
\vdots & \cdots & \ddots & \vdots \\
0 & \cdots & \cdots & \sigma_{n, t}
\end{array}\right]
$$

The vectors $a_{t}=\left[a_{21, t},\left(a_{31, t} a_{32, t}\right), \cdots,\left(a_{n 1, t} \cdots a_{n(n-1), t}\right)\right]^{\prime}$ are the equation-wise stacked free parameters of $A_{t}$ and $h_{t}=\log \left(\operatorname{diag}\left(\Sigma_{t}\right)\right)$. As suggested by Primiceri (2005) and Bianchi et al. (2009) among others, all parameters are assumed to be independent random walks 11 .

$$
\left\{\begin{aligned}
\phi_{t} & =\phi_{t-1}+\eta_{t}^{\phi} \\
a_{t} & =a_{t-1}+\varepsilon_{t} \\
h_{i, t} & =h_{i, t-1}+\eta_{t}^{h}
\end{aligned}\right.
$$

where $\phi=\left[\begin{array}{ll}\alpha_{t} & \beta_{t, p}\end{array}\right]$.

The variance-covariance matrix of innovations is block-diagonal:

$$
\left[\begin{array}{c}
\omega_{t} \\
v_{t} \\
\eta_{t}^{\phi} \\
\eta_{t}^{h} \\
\varepsilon_{t}
\end{array}\right] \sim N(0, V), \quad \text { where } V=\left[\begin{array}{ccccc}
R & 0 & \ldots & \ldots & 0 \\
0 & \Omega & \ddots & & \vdots \\
\vdots & \ddots & Q & \ddots & \vdots \\
\vdots & & \ddots & G & 0 \\
0 & \ldots & & 0 & S
\end{array}\right]
$$

\footnotetext{
${ }^{11}$ As explained in Primiceri (2005) the random walk assumption has the advantages of focusing on permanent shifts and reducing the number of parameters in the estimation procedure. However, a random walk model is nonstationary and it is obviously "more explosive" than the number of observation increases. Our sample contains no more than 200 time series observations. Using such a short period alleviates this problem.
} 
where $G=\operatorname{diag}\left(\varsigma_{1}^{2}, \ldots, \varsigma_{n}^{2}\right)$. For simplicity, it is assumed that the matrix $S$ is also block-diagonal with respect to the parameter blocks belonging to each equation.

On the other hand, $Z_{t}$ contains a set of unobservable factors of the yield curve next to observable macroeconomic factors, namely, the output gap $\left(Y_{t}\right)$, inflation $\left(\pi_{t}\right)$ and the monetary policy instrument $\left(r_{t}\right)$. As noted by Diebold et al. (2006), the intuition behind this ordering is the fact that the yield curve observations are dated at the beginning of the month. Under this identification scheme, yield factors are assumed to be contemporaneously unaffected by the macro factors.

To estimate the model we use the procedure originally suggested in Kim and Nelson (2001) and used by Bianchi et al. (2009), whereby we employ the Gibbs sampling algorithm that exploits the fact that given observations on $Z_{t}$, the model is a time-varying parameter model. In this paper preference is given to the Bayesian one-step method rather than the two-step Diebold$\mathrm{Li}$ approach because in the two-step approach the uncertainty of parameter estimation and signal extraction in the first step may affect the second step computations. However, simultaneous estimation of all parameters results in correct inferences. We follow the same basic steps of the algorithm as in Bianchi et al. (2009) whereby, first, given initial values for the factors, the VAR parameters and hyperparameters are simulated. Second, given data on $Z_{t}$ and $y(\tau)$ and a value for $\lambda$, the variance and covariance matrices are simulated. Third, conditional on all simulated parameters, factors are simulated again. Finally, the chain is started again, going back to the first step. This iterative procedure converges to an invariant density that equals the desired posterior density. Gibbs-sampling is implemented in such a way that the first 45,000 draws in the Gibbs simulation process are discarded, then the next 5,000 draws are saved and used to calculate moments of the posterior distribution.

\subsection{Priors}

We follow Primiceri (2005) and calibrate some of the prior distributions using a training sample and estimating a time-invariant VAR model by OLS. To initialize the factors and calibrate priors for the VAR, a pre-sample of three years starting in February 1985 is used. Therefore, the results presented in the following section refer to the period February 1988-October 2009. The remaining prior distributions are also chosen in a manner similar to Primiceri (2005) and 
Bianchi et al. (2009). The prior choices can be summarized as:

$$
\begin{aligned}
\phi_{0} & \sim N\left(\hat{\phi}^{O L S}, \operatorname{Var}\left(\hat{\phi}^{O L S}\right)\right) \\
\hat{A}_{0} & \sim N\left(\hat{a}^{O L S}, \operatorname{Var}\left(\hat{a}^{O L S}\right)\right. \\
h_{i, 0} & \sim N\left(\log \mu_{0}, I_{n} \times 10\right) \\
\log \psi_{0}(\tau) & \sim N\left(\log \tilde{\mu}_{0}(\tau), I_{n} \times 10\right) \\
Q_{0} & \sim I W\left(\operatorname{Var}\left(\hat{\phi}^{O L S}\right) \times 10^{-5}, T_{0}\right) \\
S_{i, 0} & \sim I W\left(\bar{S}_{i}, K_{i}\right) \\
S_{i}^{2} & \sim I G\left(\frac{10^{-4}}{2}, \frac{1}{2}\right) \\
R_{i, 0} & \sim I G\left(\frac{10^{-4}}{2}, \frac{1}{2}\right)
\end{aligned}
$$

where $T_{0}$ is a training sample. $\mu_{0}$ are the diagonal elements of $\hat{v}^{O L S}$, which is the OLS estimate of the VAR covariance matrix estimated on the training sample data. $\hat{a}^{O L S}$ denotes the off diagonal elements of $\hat{v}^{O L S} . i=1, \ldots, n$ indexes the blocks of $S . \bar{S}_{i}$ is calibrated using $\hat{a}^{\text {ols }}$. Specifically, $\bar{S}_{i}$ is a diagonal matrix with the relevant elements of $\hat{a}^{\text {ols }}$ multiplied by $10^{-3}$. Note that factor priors are obtained using the least squares estimator employed by Diebold et al. (2006) and thus $\tilde{e}_{t}(\tau)$ is obtained using the initial least squares estimates of the factors.

\section{Empirical results}

\subsection{Preliminary Empirical Results}

For the empirical analysis, we use data on the following three variables: the output gap ${ }^{12}$, the collateralized overnight call rate as an indicator of monetary policy; and inflation, measured as annualized monthly changes in the consumer price index excluding fresh food. To obtain a parsimonious specification, we choose a lag order of one, as the computations are otherwise very burdensome.

We start the analysis by examining the estimated factors which are displayed in Figure 2 together with their empirical proxies defined above. In order to evaluate the uncertainty characterizing the factors Figure 2 also plots the 16-th and 84-th quantile intervals of the standard deviation. In our case, the error bands are almost indistinguishable from the estimated series, indicating that factors are precisely estimated. However, when it comes to their empirical counterparts, the fit is at best satisfactory. Correlations between the level factor and the slope factor and their empirical counterparts are 0.76 and 0.82 , respectively. Even worse, the estimated curvature does not fit its empirical proxy well. This indicates that level and slope factors can

\footnotetext{
${ }^{12}$ The output-gap data, prepared and provided by the BOJ staff, are related to paper of Hara et al. (2006)
} 
be approximated by their corresponding empirical counterparts whereas approximations of the curvature factor are rather difficult. It is interesting to note that estimated factors start to wander from their empirical counterparts from about 1992 and to catch up with them again from 1999. We point out that this finding is not different from that of previous work as in Tam and Yu (2008).

Figure 2. Estimated factors and their empirical counterparts
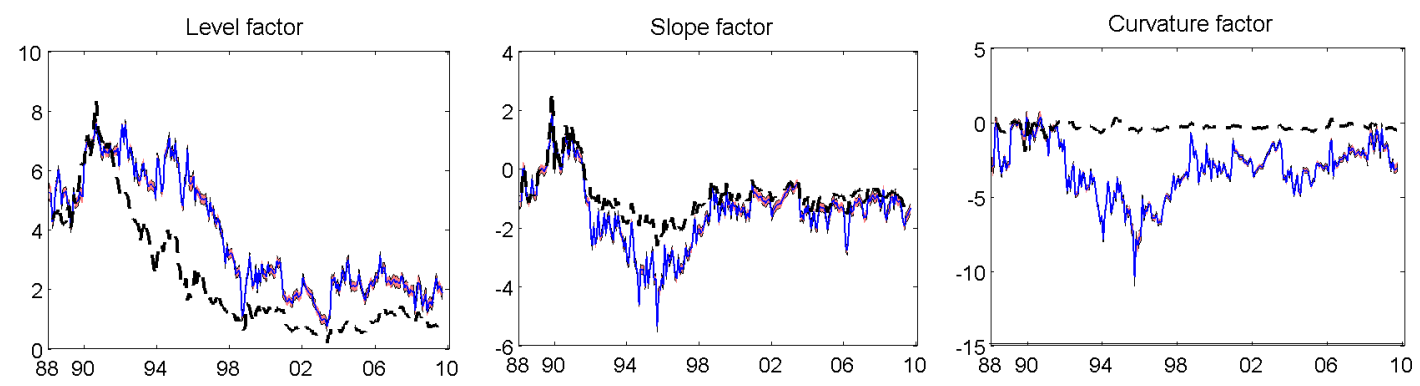

Note:In the top panel, together with factors (blue lines), the graph shows the $68 \%$ probability bands (red band) and empirical counterpart level, slope and curvature (dotted lines).

We recall that the macroeconomic interpretation to factors are as follows: the level factor is typically associated with some measure of long-run expectations of inflation ${ }^{13}$. The slope factor contains information about the expected stance of monetary policy and thus is a predictor of future economic activity and the curvature factor could also be informative about the evolution of the economy.

The error volatility has gained increasing prominence in macro-finance models. Our results support our choice of the heteroskedasticity assumption. Figure 3 plots the estimated diagonal elements of the time-varying covariance matrix. The estimated stochastic volatility of the structural shock both to factors and to the macroeconomics variables shows that the time variation of volatilities has been significant. Therefore, using the homoskedasticity assumption would result in biases in the covariance matrix for the disturbances. The time-varying volatilities of the level-and-curvature-factor shocks display a stable declining path. The volatilities of the shocks to the slope and curvature factors drop to close to zero during the zero interest rate policy (ZIRP) and QEMP periods. The stochastic volatility of the shocks to inflation declines during the same period. We observe some short-lived increases in shocks to the output gap. The largest increase occurred around the global financial crises of 2008. The volatility of the shock to the call rate is typically of the evolution of Japanese monetary policy. Call rate volatility declines up to 1995 to near zero and disappears afterwards. This reflects the decline of the call rate to $0.25 \%$ in 1995 and then within $\pm 0.25 \%$ in 1998 before the implementation of the

\footnotetext{
${ }^{13}$ It is particularly difficult to compare this factor with actual data, as information on long-run expectations is not available for Japan. Inflation-index 10-year bonds were only introduced in March 2004.
} 
ZIRP and the QEMP when the monetary policy instrument shifted from the call rate to current account balances.

Figure 3. Estimated Standard deviation of the FAVAR residuals
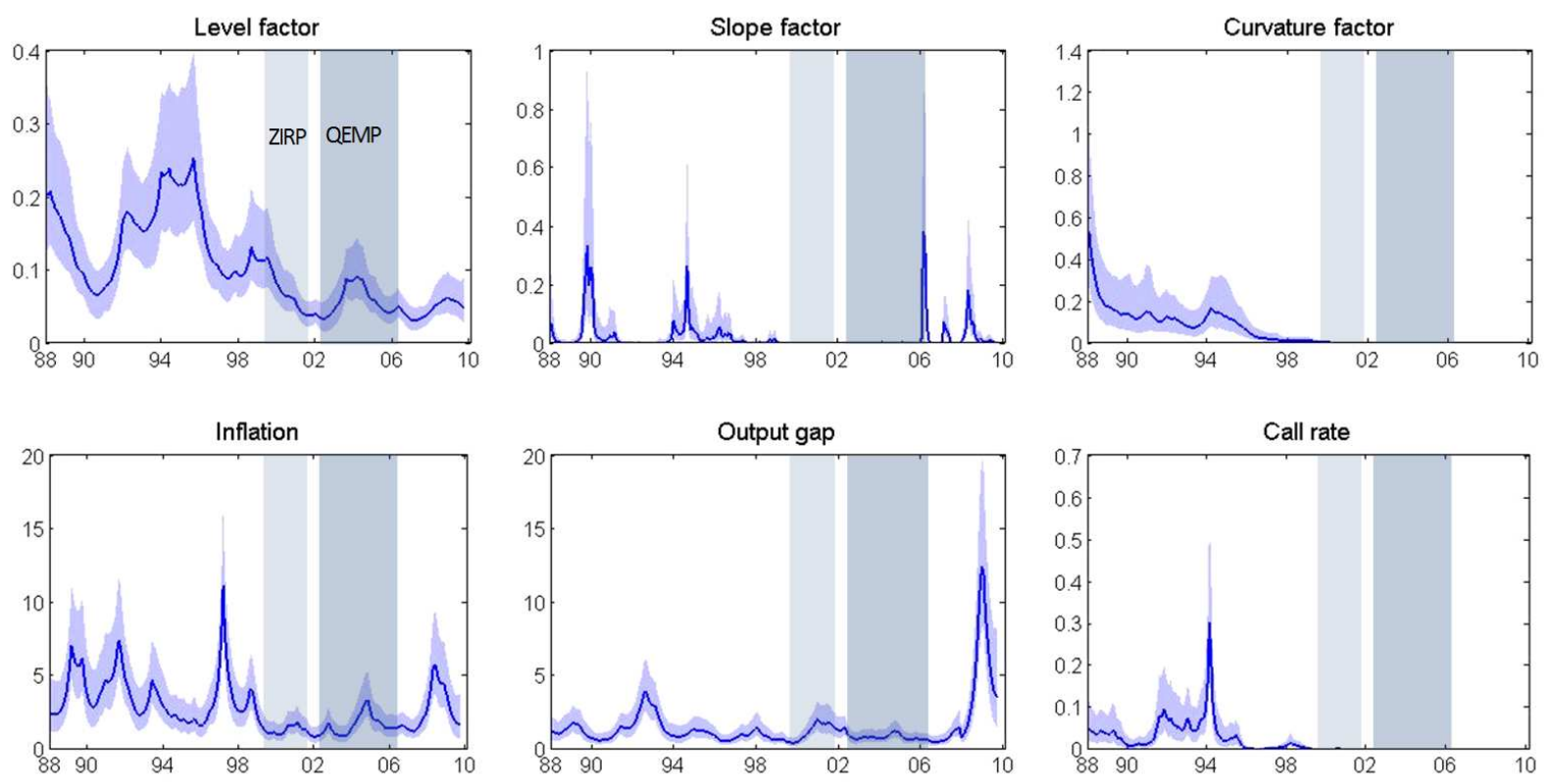

The figures show posterior means of the estimated standard deviation of the structure shocks. The solid lines show the median and the band areas represent the $68 \%$ bands.

\subsection{Evidence on the expectations hypothesis (EH)}

Empirical evidence has recently challenged the validation of the EH using Japanese data. This issue is especially important for the Japanese economy because the principal channel suggested by either ZIRP and QEMP is the expectation channel. One important channel through which monetary policy works is long-term interest rates, shaping them so that in turn they affect the level of economic activity. The expectation that a policy of low short-term interest rates may be maintained for a substantial period of time will likely lower medium- to long-term interest rates. The crucial link between a central bank's instrument and long-term interest rates is the EH of the yield curve theory. However, the empirical support for the EH and the effectiveness of the policy commitment is rather mixed. Thornton (2004) applies a bivariate VAR for long-term and short-term interest rates for the period from March 1981 to January 2003. He shows that the $\mathrm{EH}$ does not hold for the Japanese case. The author also argues that one reason why EH fails is because the term premium varies over time.

In this paper we review the validity of $\mathrm{EH}$ and the effects of the BOJ's expectations management on the JGB yield curve using a more flexible approach. Using a time-varying coefficient model we can check whether EH consistent yields track actual yields well or not. However, examining the evidence on $\mathrm{EH}$ requires separating expectations of future interest rates from the 
Figure 4. Extracted expectation component
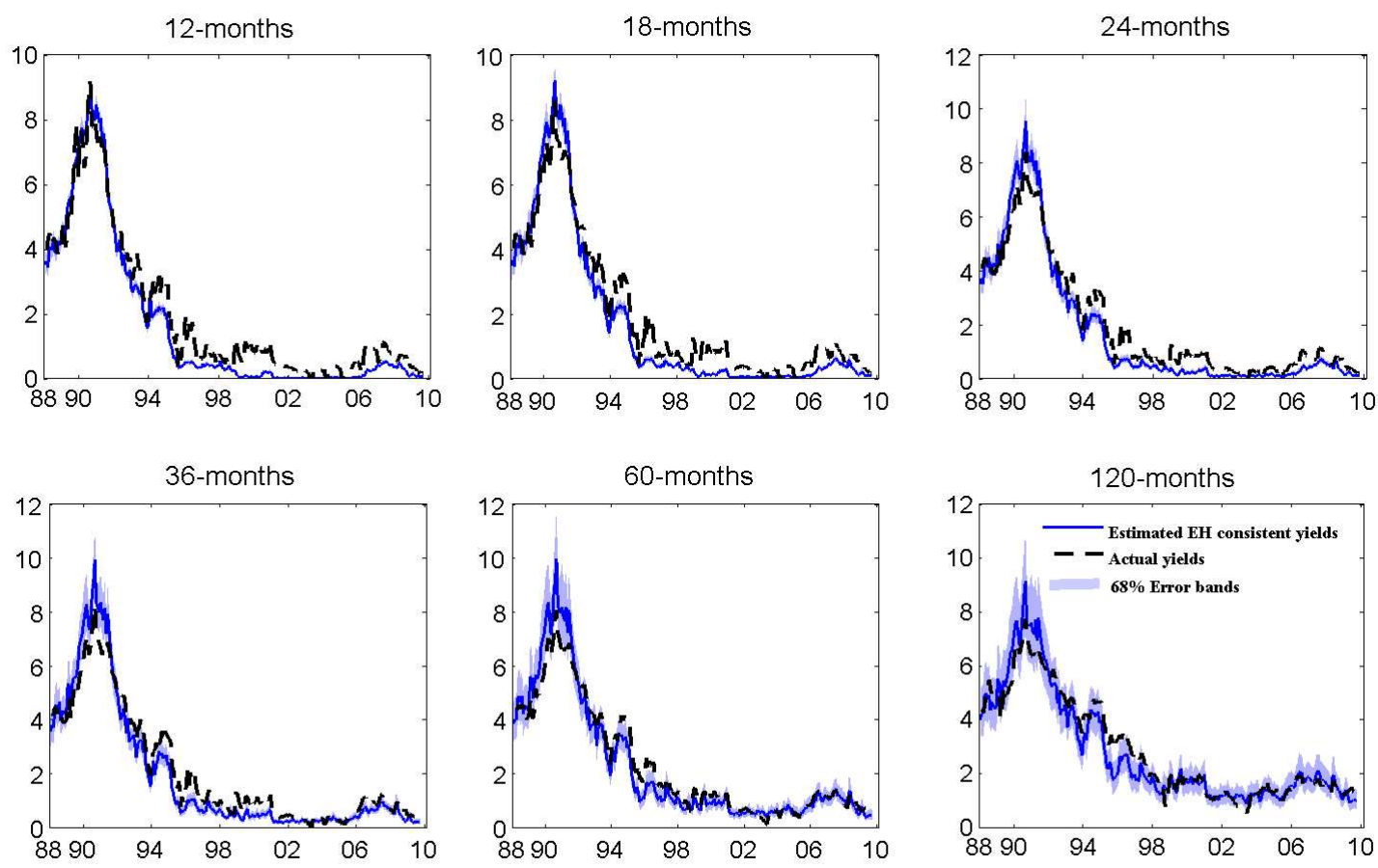

The solid lines show the median and the band areas represent the $68 \%$ bands.

term premium in the term structure. According to the EH, a long bond yield is the average of the expected short-term rates:

$$
y_{t}(\tau)^{E H}=\frac{1}{\tau} \sum_{i=0}^{\tau-1} E_{t} y_{t+i}(1)
$$

On the other hand, the interest rate risk means that investors could require additional compensation, and EH ignores this risk. The term premium, therefore, refers to this compensation and any other deviation from the EH:

$$
T P(\tau)=y_{t}(\tau)-y_{t}(\tau)^{E H}
$$

The implicit assumption behind our time-varying coefficient VAR model is that agents review their beliefs about uncertainty regarding inflation, real activity and monetary policy at each period. This assumption allows us to perform accurate predictions since it makes the model more flexible and more realistic. In addition, the term premium could vary with the business cycle, as investors might be more risk-averse in recessions than in booms. Figure 4 provides some selected maturity EH consistent yields together with their actual counterpart. The theoretical yields tracking actual yields well, despite limited deviation which occurred between 1992 and 1998 , indicate that the expectations hypothesis of the term structure of interest rates is generally supported even during the QEMP period. 


\subsection{Time-varying term premium}

According to the expectations hypothesis the term premium should simply be a function of maturities, but not a function of time. However, the empirical investigation of the expectations theory has been unsuccessful, and the hypothesis has almost always been rejected. The particular case of Japan confirms this result (Thornton (2004)). One possible explanation for the empirical failure of the $\mathrm{EH}$ is the presence a time-varying term premium. Time-variation in term premia might arise because of changes in market participant's preferred risk aversion. Moreover, a standard finding in the literature is that term premia are countercyclical; they seem to be highest during and immediately after recessions and lowest in booms (see, for example, Cochrane and Piazzesi (2005)).

Figure 5. Estimated term premium
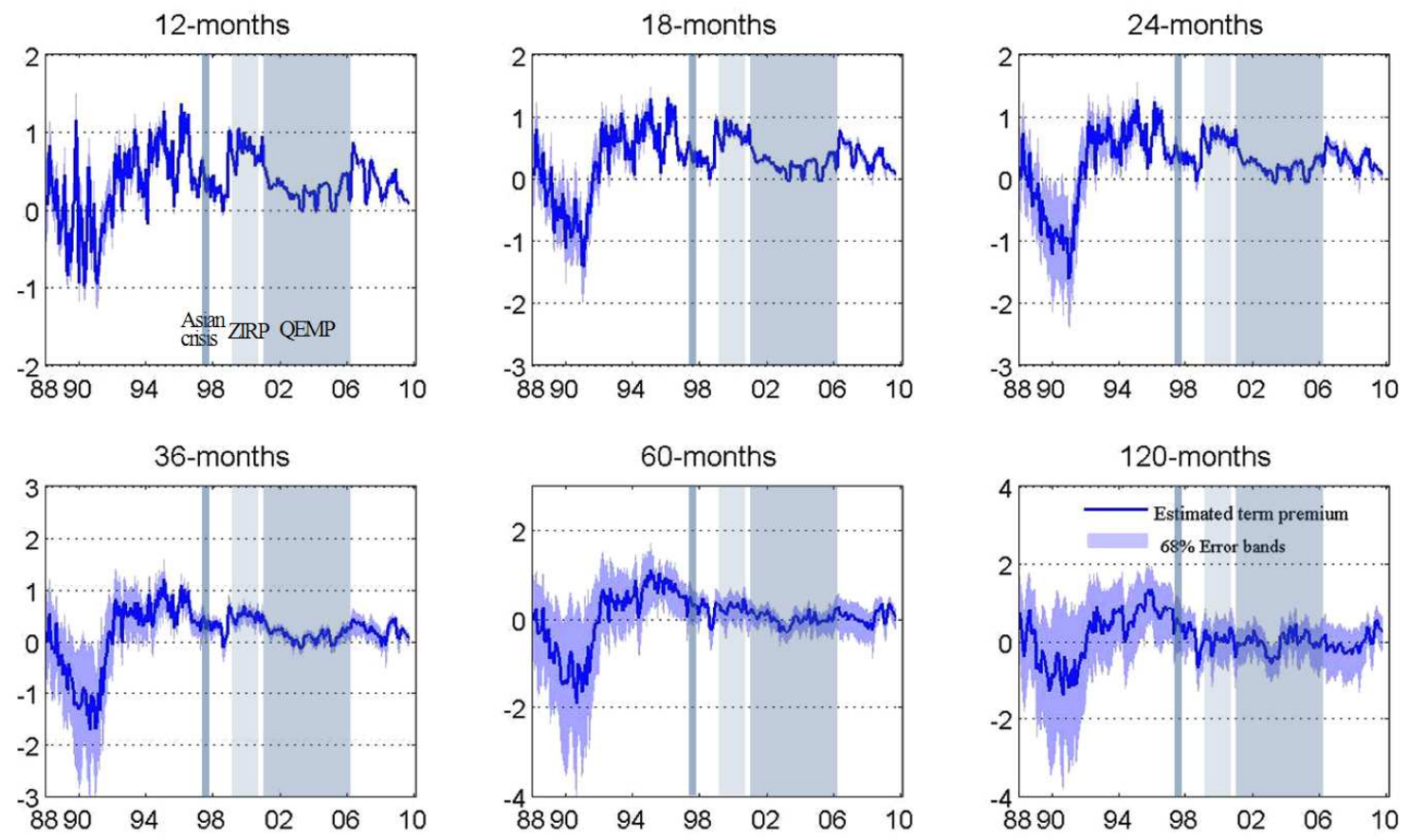

The solid lines show the median and the blue areas indicate the 16th and 84th percentiles of the term premium.

Estimated term premia of some selected maturities are shown in Figure 5. There appears to be a structural break in the behavior of the term premium for all maturities- in particular, volatility and magnitude have subsided since 1998. The particular episode of large decrease in term premia between 1989 and 1992 may be explained by the heavy demand for JGBs during the burst of the asset price bubble. A second episode of positive term premia coincides with Japan's economy stagnation from 1992 to 1999. When real GDP showed a slight recovery phase in 1999, term premia declined and even started to fluctuate around zero over the rest of the sample for longer maturities. It is interesting to note that during the quantitative easing 
period between 2001 and 2006 term premia decline to a lower level. This could be due to the heavy demand for JGBs from the BOJ during that period. Another explanation of the decline of term premia is that it could reflect a global decline in risk and term premia in developed and emerging market economies at that time. ? argue that global banking sector liabilities due to foreign creditors, called "non-core liabilities", increased rapidly from 2003 up to the financial crisis in 2008. The authors show that the banking sector relies more on funding from foreign creditors when global economic conditions are favorable since private sectors' deposits are not enough to sustain banks' desired balance sheets expansions. These additional funds are invested in a variety of assets such as corporate and government securities, lowering yields and risk premia in these assets.

\subsection{Empirical Results From the Macro-Finance Model}

\subsubsection{Are monetary policy shocks an important source of variation in the yield curve?}

Given the focus of this paper on the effects of monetary policy on the yield curve, the discussion is focused on the decomposition of the unconditional variance of selected endogenous variables into contributions from the monetary policy shocks 14 .

The variance decomposition of the call rate ${ }^{15}$, shown in Figures 6 , identifies the contribution of the monetary policy shock to variations in the yield curve and macroeconomic variables. The variance decomposition implies that a variation in the call rate is largely due to independent monetary policy shocks. However, during the QEMP period (between 2001 and 2006) the contribution of the policy shock is negligible. This is consistent with the change in monetary policy instrument from call rate to current account balances by the adoption of the quantitative easing strategy. After 2006 the contribution of monetary policy shocks to the policy interest rate becomes again important. The monetary policy rate shock accounts at most for $20 \%$ of the fluctuations in output until 1995, around the time when the BOJ dropped its interest rate to $0.5 \%$. The contribution has been negligible afterwards. Innovations to call rate makes the largest contribution to the variance of inflation during the period between 1988 and the end of 1994, after which it veers to almost zero. A similar patern emerges in its contribution to the fluctuations in level, slope and curvature factors.

Looking at the variance decomposition of inflation shocks, displayed in Figure 10, it is apparent that inflation does not explain a large part of yield curve factors. The largest contri-

\footnotetext{
${ }^{14}$ The proportion of the unconditional variance accounted for by monetary policy shock is calculated as the ratio of the unconditional variance due to the shock of interest rate and the total unconditional variance. For more details see Bianchi et al. (2009).

${ }^{15}$ Using call rate as monetary policy instrument during the QEMP may be subject to criticism since the BOJ is targeting the monetary base. But, as demonstrated in Nagayasu (2004), the BOJ had to practice a strong smoothing of interest rates in order to keep the short-term rate near to zero during this period.
} 
Figure 6. Unconditional variance - Call rate shock.
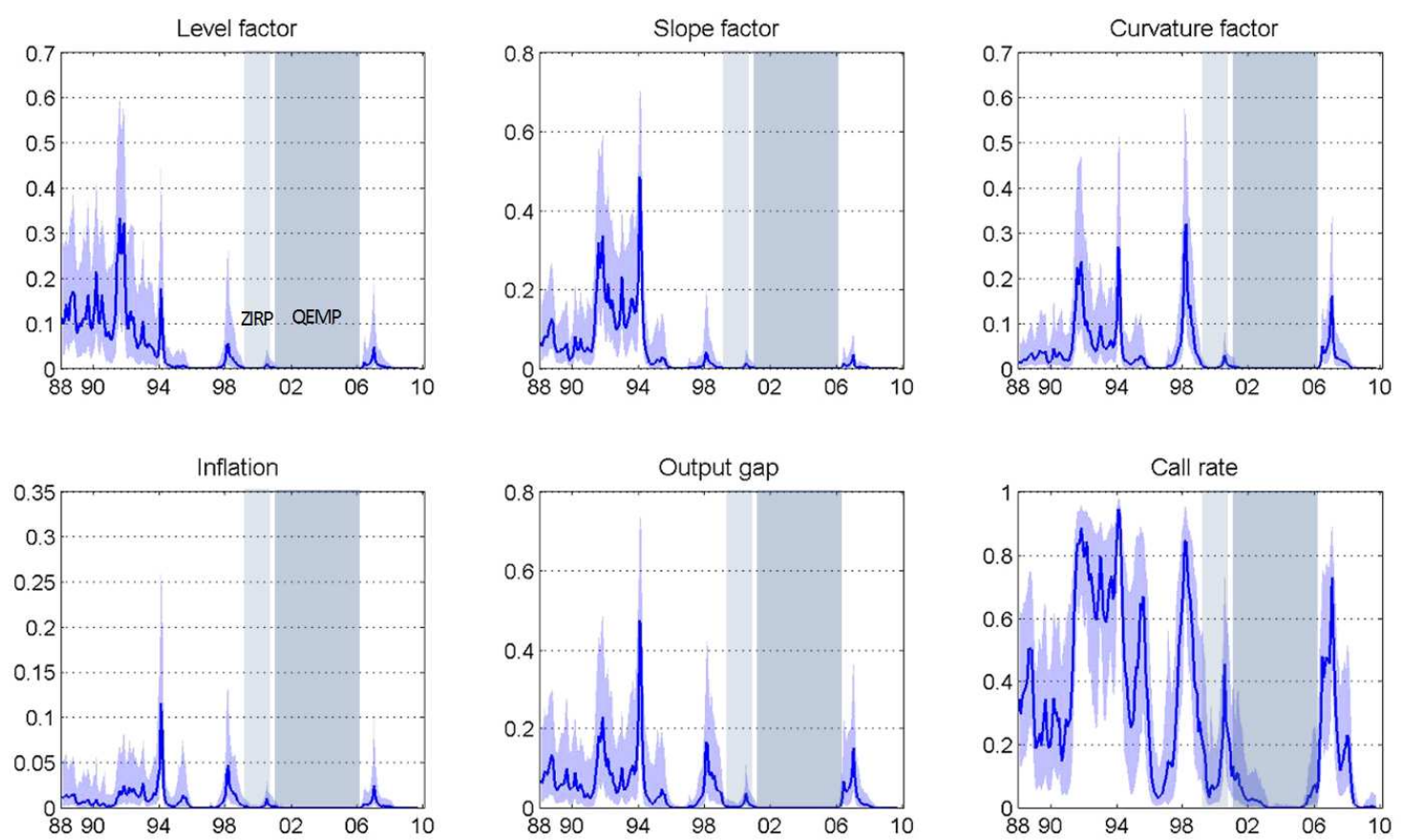

The figures show the variable contributions to the monetary policy rate variation. The solid line denotes the median estimate, while the band indicates the $16 \%$ and the $84 \%$ quantiles of the posterior distribution of variance decompositions.

bution was in the early 1990s after which it became negligible. However, Figure 11 shows that variances in level and slope factors are significantly explained by the variance in the output gap until 1994, which accounts for approximately $30 \%$ and 40\%, respectively. This indicates that news about the future evolution of output might be more important for the dynamics of the yield curve than inflationary concerns for that period. This contribution quickly shifted to very low levels over the period between 1995 and 2006 after which it rose to similar levels as before. Altogether, these results suggest a negligible role of macroeconomic variables in influencing the yield curve during the long-lasting economic stagnation between 1995 and 2006.

Figure 7 complements the variance decomposition by displaying the impulse response functions of the yield-curve factors and the macroeconomic variables to a monetary policy shock ${ }^{16}$. We recall that the ultimate objective of the Japanese monetary policy is to affect the yield curve level in order to stimulate the economy and to achieve low and stable inflation. More precisely, we focus on the effectiveness of the QEMP in affecting the long-end of the yield curve. Before turning to the impulse responses following a surprise change of the monetary policy rate, it is worth calling attention to the difficult interpretation of the level factor

\footnotetext{
${ }^{16}$ For the sake of brevity, we only report the impulse response functions of the key variables to a chock to monetary policy. Results of impulse response functions to shock to the slope, curvature, output and inflation are available upon request from the authors.
} 
reaction. Indeed, the success of monetary policy could be defined as a decrease in the long-end of the yield curve via either expected short-term rates (policy-duration effect), term premium (portfolio-rebalancing channel) or both of them. However, this represents only an intermediate target in an attempt to generate economic recovery and to stop deflation. Therefore, the definition of a successful policy may be subject to criticism since economic recovery, the final goal of the BOJ, is expected to increase inflation expectations and thus future short-term interest rates, which in turn will raise long-term interest rates. As argued by Nagayasu (2004) monetary policy mechanisms take one to two years to achieve their full effects. It seems appropriate, at the time of writing, to expect that the effectiveness of QEMP, if any, would result in an increase of the level factor.

Figure 7. Impulse responses - Call rate shock
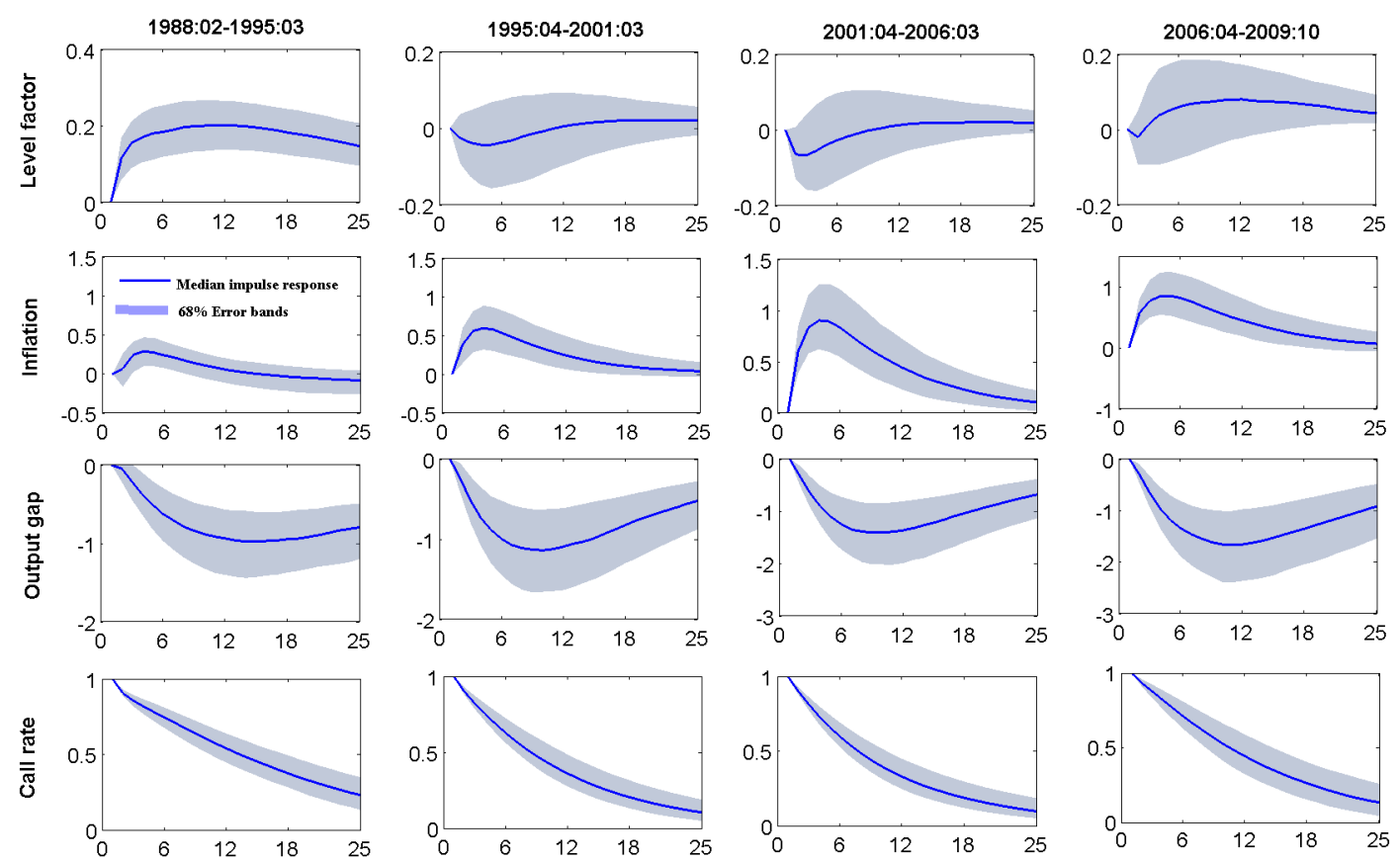

The figure shows the reactions of inflation, output and level factor to a shock to the call rate over 25 months for three sample periods. The solid lines show the impulse responses implied by the timevarying VAR following a rise by 100 basis point in call rate. The impulse responses in each sub-sample are average of the impulse response in each month in that sample. The band areas represent $68 \%$ error bands.

We report the responses for four sub-periods covering different main measures implemented by the BOJ to stimulate the economy. The period between 1988 and 1994 represents the period of high short term interest rate. The 1995-2001 period covers the so called transition period and the ZIRP period. The third and fourth sub-periods represent respectively the QEMP period and after the exit from this strategy.

Consider the reaction of key variables to a monetary policy shock. Impulse response functions of the level factor indicate a significant and persistent increase of the level factor during 
the 1988-1995 period. During that period short-term interest rates were still high and had a potent dynamic effect on the level of the yield curve. However, during the period of low interest rates, specially the QEMP period, the effect of the call rate on the level factor becomes insignificant. This finding is consistent with previous research (Okina and Shiratsuka (2004), Nagayasu (2004) and others) and corroborates the idea that under the zero lower bound, and according to the expectation hypothesis, the expected future short-rate becomes equal to zero and then the long-term interest rate becomes equal to the expected future term premium. In this case it becomes more difficult for the central bank to influence long-term interest rates. However, while statistically insignificant, the decline in the level factor, which is more pronounced during the QEMP period, may reflect the strengthening credibility of the BOJ and thus the effectiveness of its policy. Indeed, as argued in Diebold et al. (2006) and Bianchi et al. (2009), if monetary policy is credible the level factor, everything being equal, should fall after a positive shock to call rate, because the expectation of future inflation declines. Since the BOJ commits itself during the QEMP period to maintaining the short-term rates to a zero level, the decline in the level factor after an increase in the call rate is by analogy equivalent to a rise in this factor to a monetary policy expansion. This can be due to an expectation of an economic recovery and an inflation rise, indicating a monetary policy success.

The reaction of inflation suggests a strong evidence of a price puzzle regardless of the sample period ${ }^{17}$. The magnitude of the positive response is smaller over the high-interest-rates period (1988-1995); the inflation response veers to zero and becomes insignificant more rapidly. The call rate shock still has a negative effect on the output gap with a more persistent response over the periods before 1995 and after 2006.

\subsubsection{Is there a feedback effect from the yield curve to macroeconomic variables?}

The variance decomposition of the level factor, shown in Figure 8 , implies that the shock to the level factor has the strongest impact on the long end of the yield curve. During the period between 1995 and 2006 level shocks account for more than $90 \%$ of all level-factor variation. This suggests a large amount of idiosyncratic variation in the long end of the yield curve that is unrelated to macroeconomic fundamentals. This shock explains at most $5 \%$ of the variance in inflation and $10 \%$ of the variance in the output gap. The increasing contribution of this shock to the call rate since 1995 is matched by the contribution of the slope factor. These results reflect the increasing emphasis on long-term interest rates by the monetary policy stance during the quantitative easing period. Taken together, financial shocks do not explain much of the variance in macroeconomic variables. These results are not surprising in the case of Japan as the relation between the yield curve and macroeconomic variables largely depends on financial

\footnotetext{
${ }^{17}$ The price puzzle problem can be due to the lack of information included in the VAR system as explained in Bernanke et al. (2005), or to the small number of lags chosen given the model complexity
} 
Figure 8. Unconditional variance - level factor shock
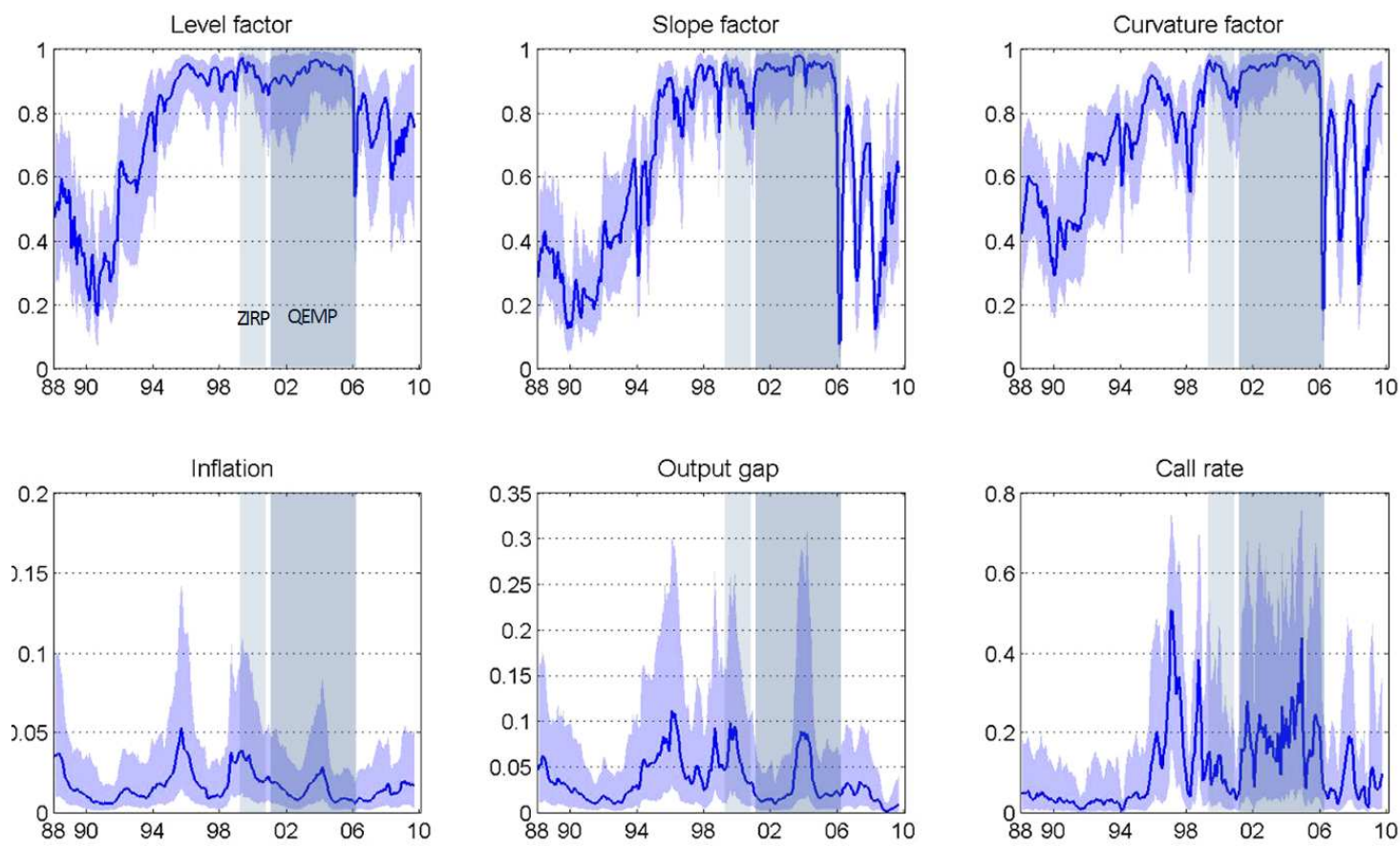

The figures show the variable contributions to the level factor variation. The solid line denotes the median estimate, while the band indicates the $16 \%$ and the $84 \%$ quantiles of the posterior distribution of variance decompositions.

system conditions for the reasons explained in section 4.1.

Figure 9 summarizes impulse response functions to an unexpected increase of the level factor. A positive surprise change of the level factor indicates an increase of inflation during the period before 1995 and after 2006, but this effect remains insignificant. However, by contrast with the conventional wisdom, in both periods of low interest rates, including the QEMP period, inflation decreases immediately in reaction to the level factor shock and reverts towards zero. The level shock has a positive effect on output gap, although its impact seems to exhibit time variation. During the period between 1995 and 2006 output gap reacts significantly reinforcing our finding that the contribution of macroeconomic variables to level factor variation, if any, comes from output gap.

Figure 14 plots responses to an unexpected positive change of the slope factor. An increase in the slope factor means a reduced spread between long-term and short-term bonds, which indicates a monetary policy tightening and thus a decline of economic activity ${ }^{18}$. The direction of the reaction of the output gap corroborates this view, while its responses are shortlived and hardly significant. The reaction of inflation looks qualitatively similar to the response

\footnotetext{
${ }^{18}$ Normally a decreasing yield curve slope announces an economic slowdown. But since the loading of the slope factor in our model decreases with maturity and corresponds to the difference between short- and long-term yields, an increase in this factor corresponding therefore to a decrease in the term spread.
} 
to a level shock. An unexpected increase of the slope factor is followed by an initial decrease of inflation for all sub-samples. The call rate rises after the slope shock but its reaction is not significant except during the first period of high interest rates. Altogether, the impulse response functions reinforce results from variance decompositions that the yield curve is not informative about macroeconomic variables when interest rates decline to a very low level and specially during the quantitative easing period.

Figure 9. Impulse responses - Level shock
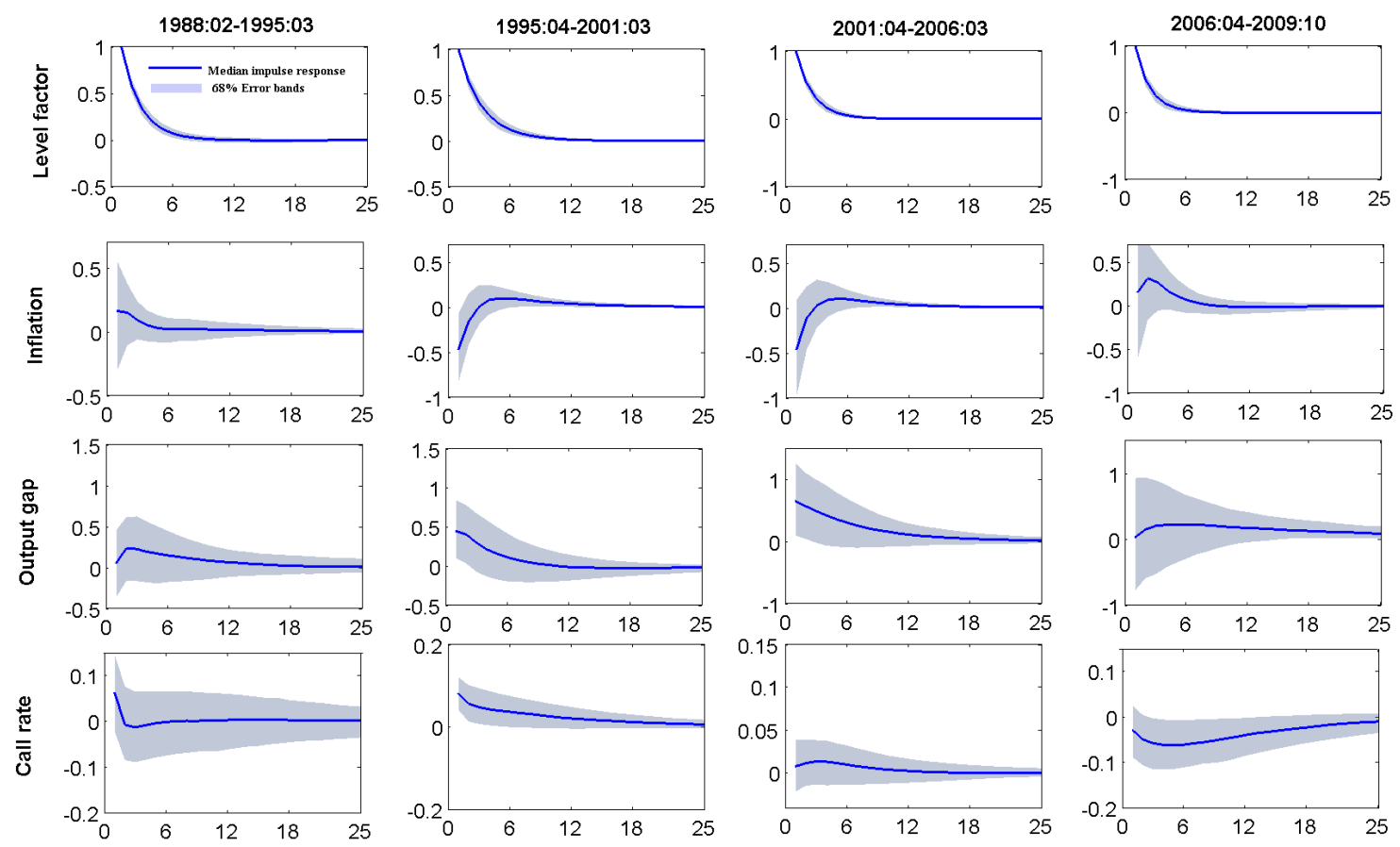

The figures show the reactions of inflation, output gap and call rate to a shock to the level factor over 25 months for three sample periods. The solid lines show the impulse responses implied by the timevarying VAR following a rise by 100 basis point in call rate. The impulse responses in each sub-sample are average of the impulse response in each month in that sample. The band areas represent $68 \%$ error bands. 


\section{Conclusion}

This paper has examined the effects of the quantitative easing strategy in Japan on the yield curve and the possible feed-back effect by applying a macro-finance model that allows for time-varying parameters. This model provides maximum flexibility in measuring the effect of macroeconomic variables on the yield curve and vice-versa. It incorporates three macroeconomic variables, namely the output gap, inflation and the call rate, and three yield curve factors which represent level, slope and curvature, summarizing the term structure of interest rates. Before estimating this model, we constructed a database of zero-coupon yields using Japanese government bond price data for the period between 1985 and 2009. In order to estimate the spot rate curve we applied the smoothing B-splines method and imposed non-negative spot restrictions in the estimation procedure. We thus avoid having negative spot rates during the lower short-term interest rate period.

Contrary to the results of standard term-structure models with a time-invariant term premium, our results show that the expectations hypothesis of the term structure of interest rates is generally supported, even during the QEMP period. Empirical results from a macro-finance model show that the relationship between the macroeconomic and financial variables has changed significantly over time. There is hardly any relationship at the zero lower bound on interest rates and deflation, and especially during the quantitative easing period. The structural decomposition of the yield curve into its macroeconomic components shows that, by contrast with conventional wisdom, inflation, activity and monetary policy play a less prominent role in explaining the yield curve. They play no role at all particularly during quantitative easing. The variance decomposition of the level factor indicates that the main part of the variation in this factor comes from the yield curve factors, limiting the contribution of macroeconomic variables. Conversely, the relative importance of yield curve factors in the variation of inflation is relatively small and even inexistent during quantitative easing. A more pronounced effect of yield curve factors on the output gap is detected during the period of high interest rates, and this effect disappears during quantitative easing. Moreover, the increasing contribution of the level factor in the variation of the call rate during quantitative easing reflects the increasing importance attributed by monetary policy to long-term interest rates. These finding are corroborated by impulse response results.

As the objective of the BOJ during the quantitative-easing regime is to affect long-term interest rates in order to stimulate the economy, a credible and successful expansionary policy is a policy resulting in a rise in the level factor due to a recovery and inflation expectations. This is equivalent to a decline in the level factor following a positive shock to the call rate. Impulse response analysis shows that during this period, while statistically insignificant, the level factor declines in response to a positive shock to the call rate. This may be due to an expectation of an 
inflation rise and an economic recovery, indicating increasing credibility leading to monetary policy success.

On the other hand, the insignificant effect of the call rate on the level factor can be explained by the fact that, at the zero lower bound of interest rates, expected future short-term rates are almost zero and long-term interest rates become largely determined by the forward term premium, which the BOJ finds difficult to influence. A focus on term premium and expectation components would better capture the effect of monetary policy on yield curve. In addition, according to Bernanke et al. (2005), simple variables alone cannot represent economic concepts like activity or price. The alternative is then to use a model with macroeconomic factors summarizing a larger set of macroeconomic variables. These issues could well benefit from research attention in the future. 


\section{References}

Ang, Andrew, and Piazzesi, Monika. 2003. A no-arbitrage vector autoregression of term structure dynamics with macroeconomic and latent variables. Journal of Monetary Economics, 50(4), $745-787$.

Baba, Naohiko, Nishioka, Shinichi, Oda, Nobuyuki, Shirakawa, Masaaki, Ueda, Kazuo, and Ugai, Hiroshi. 2005. Japan's Deflation, Problems in the Financial System, and Monetary Policy. Monetary and Economic Studies, 23(1), 47-111.

Bernanke, Ben, Boivin, Jean, and Eliasz, Piotr. 2005. "Measuring the Effects of Monetary Policy: A Factor-augmented Vector Autoregressive (FAVAR) Approach". The Quarterly Journal of Economics, 120(1), 387-422.

Bianchi, Francesco, Mumtaz, Haroon, and Surico, Paolo. 2009. The great moderation of the term structure of UK interest rates. Journal of Monetary Economics, 56(6), 856-871.

BIS. 2005. Zero-coupon yield curves: technical documentation. Bank for International Settlements, technical documentation, No 25, October.

Cargill, Thomas F., Hutchison, Michael M., and Ito, Takatoshi. 2001. Financial Policy and Central Banking in Japan. MIT Press Books, vol. 1, no. 0262032856. The MIT Press.

Cochrane, John H., and Piazzesi, Monika. 2005. Bond Risk Premia. American Economic Review, 95(1), 138-160.

Cogley, Timothy, Morozov, Sergei, and Sargent, Thomas J. 2005. Bayesian fan charts for U.K. inflation: Forecasting and sources of uncertainty in an evolving monetary system. Journal of Economic Dynamics and Control, 29(11), 1893 - 1925.

Diebold, Francis X., Rudebusch, Glenn D., and Borag[caron]an Aruoba, S. 2006. The macroeconomy and the yield curve: a dynamic latent factor approach. Journal of Econometrics, 131(1-2), 309-338.

Eggertsson, Gauti B., and Woodford, Michael. 2003. The Zero Bound on Interest Rates and Optimal Monetary Policy. Brookings Papers on Economic Activity, 34(2003-1), 139-235.

Evans, Charles L., and Marshall, David A. 2007. Economic determinants of the nominal treasury yield curve. Journal of Monetary Economics, 54(7), 1986-2003.

Fisher, Mark, Nychka, Douglas, and Zervos, David. 1995. Fitting the term structure of interest rates with smoothing splines. Finance and Economics Discussion Series 95-1. Board of Governors of the Federal Reserve System (U.S.). 
Fujiwara, Ippei. 2006. Evaluating monetary policy when nominal interest rates are almost zero. Journal of the Japanese and International Economies, 20(3), 434-453.

Girardin, Eric, and Moussa, Zakaria. 2010. Quantitative easing works: Lessons from the unique experience in Japan 2001-2006. GREQAM working paper, 2010-02. http: //www.greqam.fr/spip.php?article7099\&lang=fr.

Gorovoi, Viatcheslav, and Linetsky, Vadim. 2004. Black's Model of Interest Rates as Options, Eigenfunction Expansions and Japanese Interest Rates. Mathematical Finance, 14(1), 49-78.

Hara, N., Hirakata, N., Inomata, Y., S., Ito, Kawamoto, T., Kurozumi, T., Minegishi, M., and Takagawa, I. 2006. The New Estimates of Output Gap and Potential Growth Rate. Bank of Japan, Research and Statistics Department. Working Papers.

Inoue, Tomoo, and Okimoto, Tatsuyoshi. 2008. Were there structural breaks in the effects of Japanese monetary policy? Re-evaluating policy effects of the lost decade. Journal of the Japanese and International Economies, 22(3), 320-342.

Kim, Chang-Jin, and Nelson, Charles R. 2001. A Bayesian Approach to Testing for MarkovSwitching in Univariate and Dynamic Factor Models. International Economic Review, 42(4), 989-1013.

Krugman, Paul. 2000. Thinking About the Liquidity Trap. Journal of the Japanese and International Economies, 14(4), 221-237.

Metzler, Allan. 1995. Monetary, Credit and (Other) Transmission Processes: A Monetarist Perspective. Journal of Economic Perspectives, 9(4), 49-72.

Miyao, Ryuzo. 2000. The Role of Monetary Policy in Japan: A Break in the 1990s? Journal of the Japanese and International Economies, 14(4), 366-384.

Nagayasu, Jun. 2004. The Term Structure of Interest Rates and Monetary Policy during a Zero Interest Rate Period. Monetary and Economic Studies, 22(2), 19-43.

Nakajima, Jouchi, Kasuya, Munehisa, and Watanabe, Toshiaki. 2009. Bayesian Analysis of Time-Varying Parameter Vector Autoregressive Model for the Japanese Economy and Monetary Policy. IMES Discussion Paper Series, May.

Nakajima, Jouchi, Shiratsuka, Shigenori, and Teranishi, Yuki. 2010. The Effects of Monetary Policy Commitment: Evidence from Time- varying Parameter VAR Analysis. IMES Discussion Paper Series. Institute for Monetary and Economic Studies, Bank of Japan.

Nelson, Charles R, and Siegel, Andrew F. 1987. Parsimonious Modeling of Yield Curves. Journal of Business, 60(4), 473-89. 
Oda, Nobuyuki, and Ueda, Kazuo. 2007. The Effects Of The Bank Of Japan'S Zero Interest Rate Commitment And Quantitative Monetary Easing On The Yield Curve: A MacroFinance Approach. The Japanese Economic Review, 58(3), 303-328.

Okina, Kunio, and Shiratsuka, Shigenori. 2004. Policy commitment and expectation formation: Japan's experience under zero interest rates. The North American Journal of Economics and Finance, 15(1), 75-100.

Primiceri, Giorgio E. 2005. Time Varying Structural Vector Autoregressions and Monetary Policy. Review of Economic Studies, 72(3).

Rudebusch, GlennD., and Wu, Tao. 2008. A Macro-Finance Model of the Term Structure, Monetary Policy and the Economy. Economic Journal, 118(530), 906-926.

Tam, Chi-Sang, and Yu, Ip-Wing. 2008. Modelling sovereign bond yield curves of the US, Japan and Germany. International Journal of Finance and Economics, 13(1), 82-91.

Thornton, Daniel-L. 2004. Testing the Expectations Hypothesis: Some New Evidence for Japan. Monetary and Economic Studies, 22(2), 45-69.

Ueno, Y., Baba, N., and Sakurai, Y. 2006. The Use of the Black Model of Interest Rates as Options for Monitoring the JGB Market Expectations. Working paper. Institute for Monetary and Economic Studies, Bank of Japan.

Ugai, Hiroshi. 2007. Effects of the Quantitative Easing Policy: A Survey of Empirical Analyses. Monetary and Economic Studies, 25(1), 1-48. 


\section{Figures}

Figure 10. Variance decomposition due to inflation
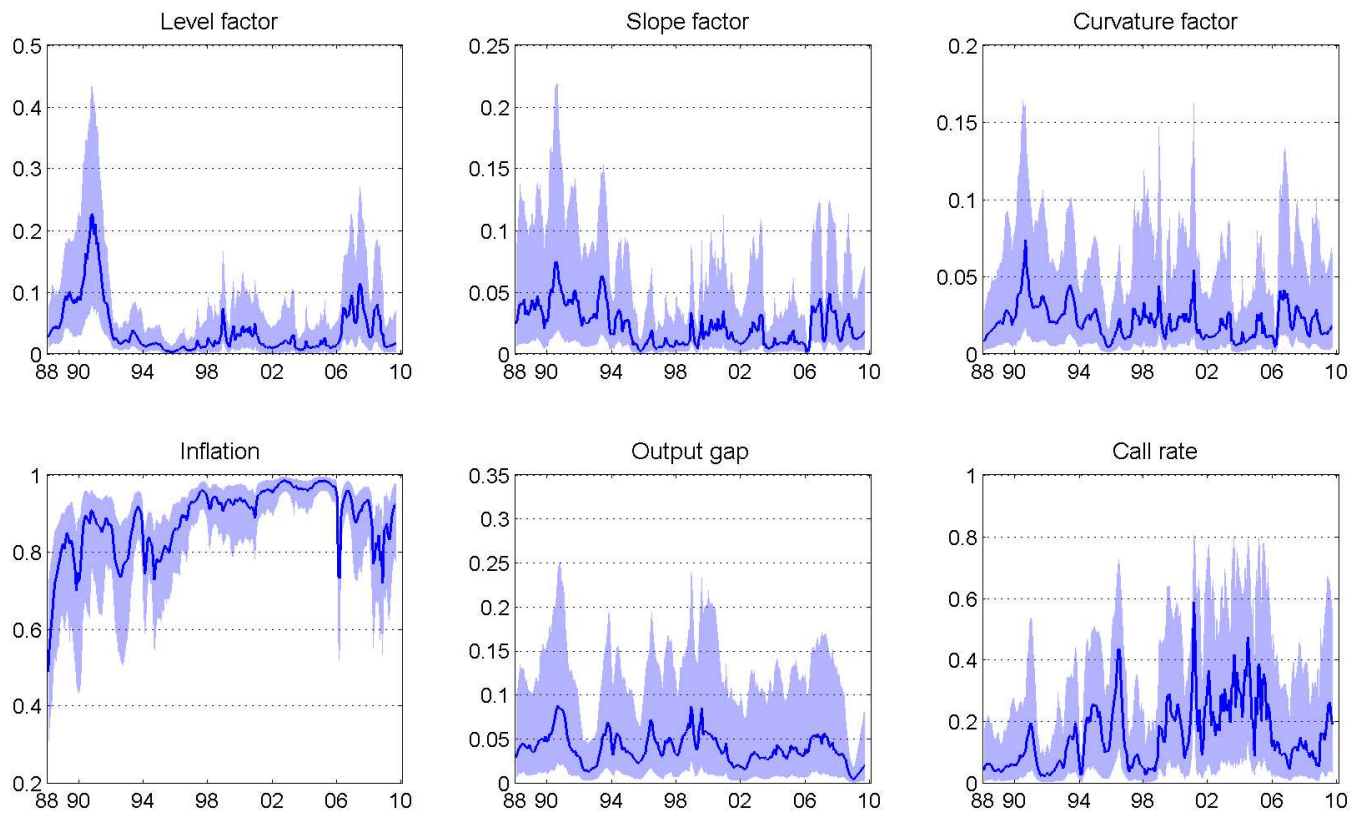

Unconditional variance due to the inflation shock. The graph shows the percentage of the variance of each of the variables that explained by the inflation shock. 
Figure 11. Variance decomposition due to the output gap
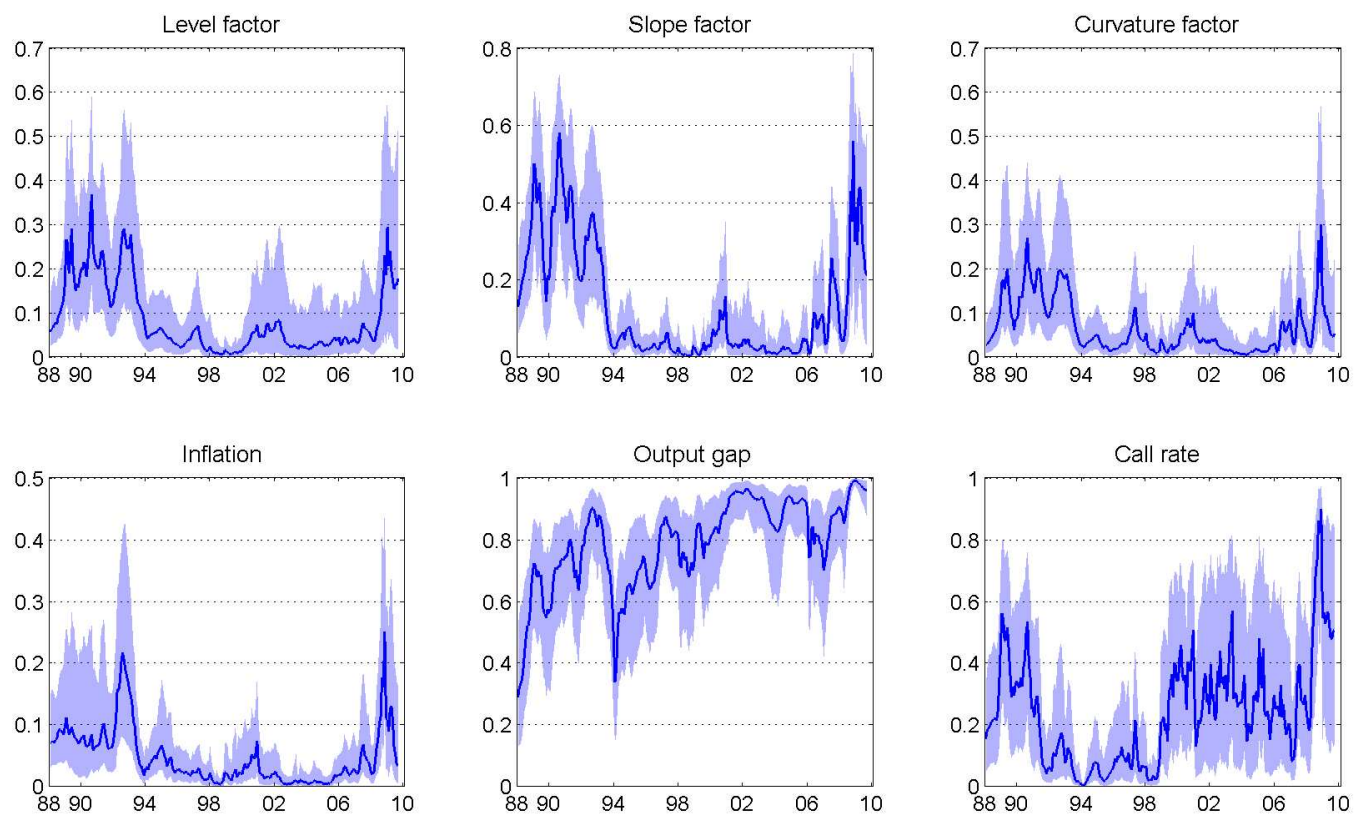

Unconditional variance due to the output gap shock. The graph shows the percentage of the variance of each of the variables that explained by the output gap shock.

Figure 12. Variance decomposition due to slope factor
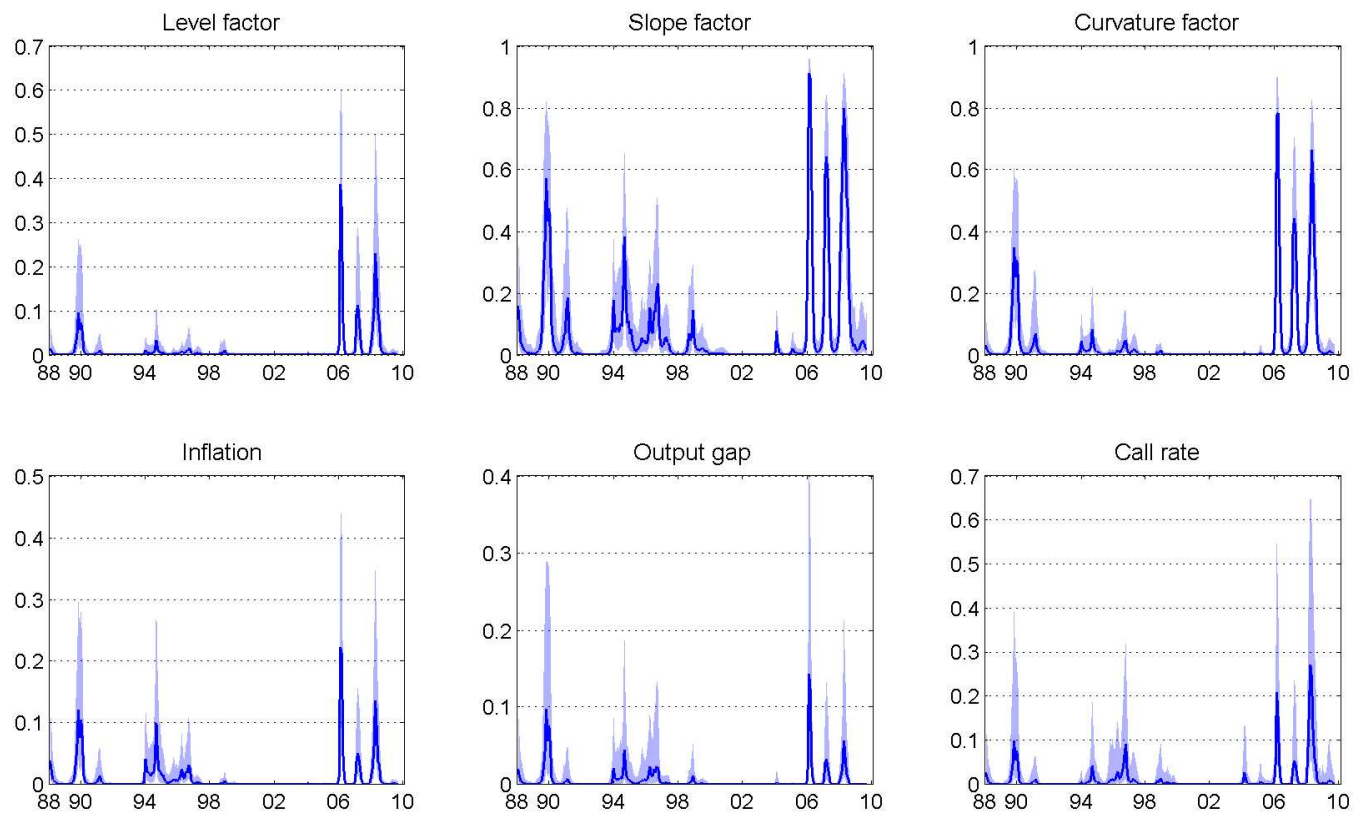

Unconditional variance due to the slope factor. The graph shows the percentage of the variance of each of the variables that explained by the slope factor shock. 
Figure 13. Variance decomposition due to curvature
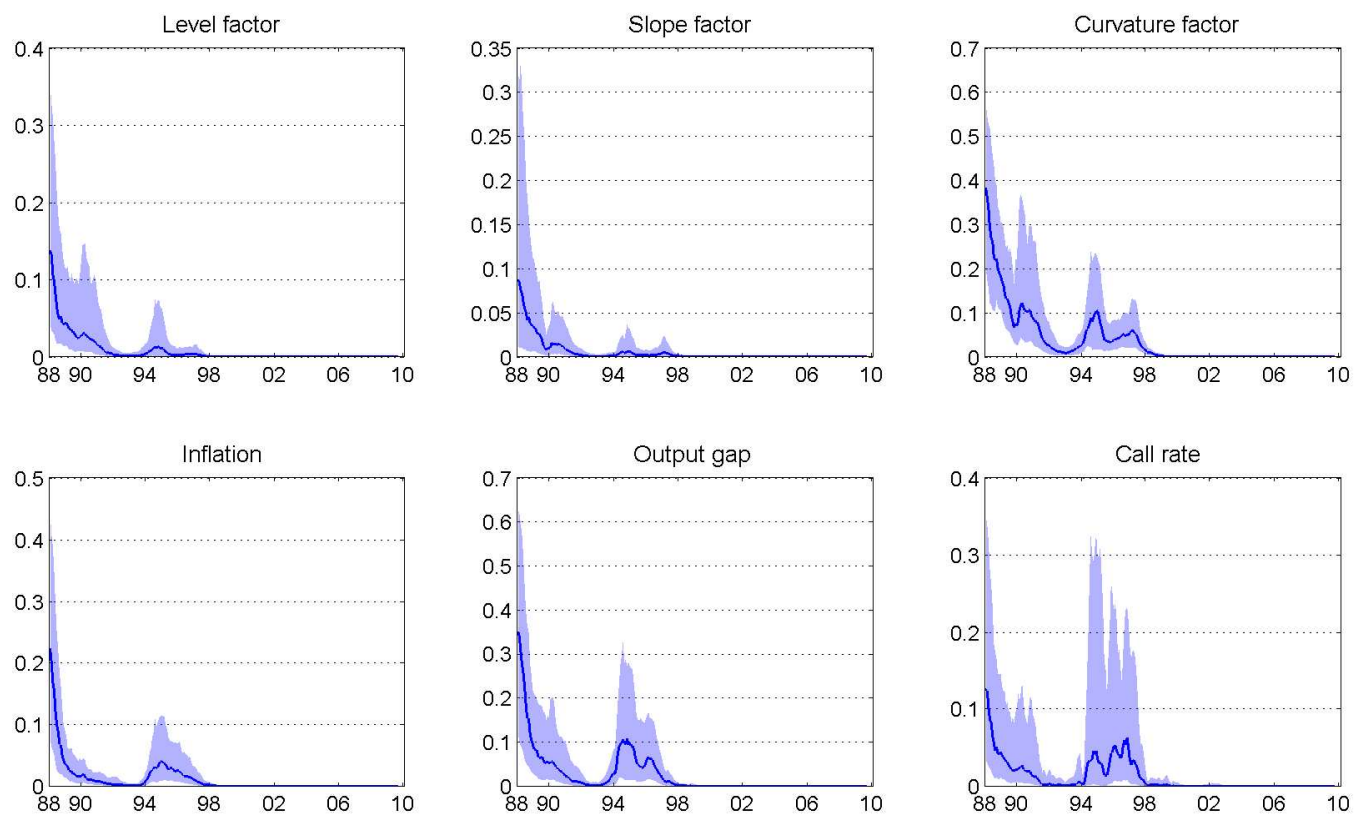

Unconditional variance due to the curvature factor. The graph shows the percentage of the variance of each of the variables that explained by the curvature shock. 
Figure 14. Impulse response functions to slope shock
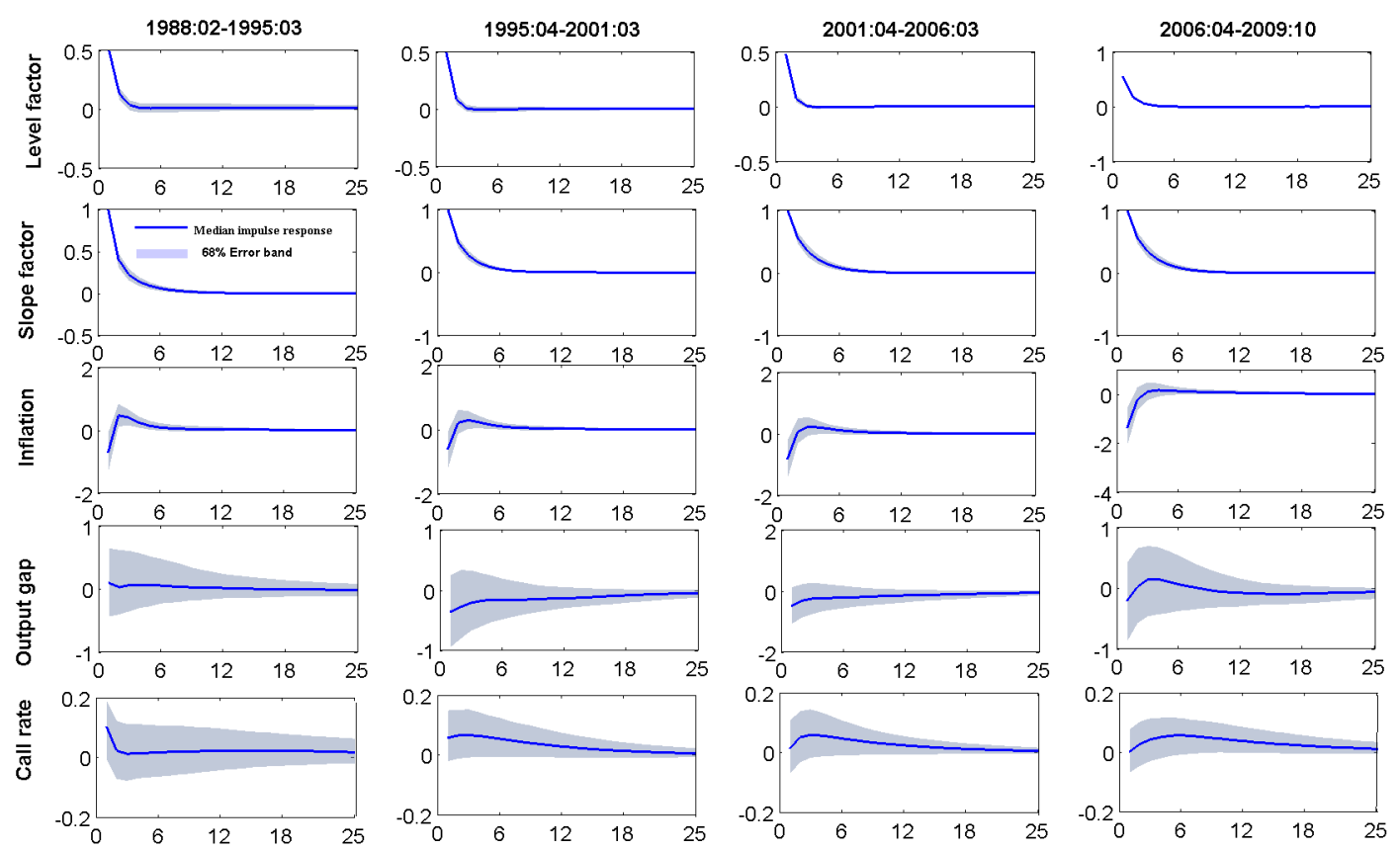

The figures show the reactions of level factor, inflation, output and call rate to a shock to the slope factor over 25 months for three sample periods. The solid lines show the impulse responses implied by the time-varying VAR following a rise by 100 basis point in call rate. The impulse responses in each sub-sample are average of the impulse response in each month in that sample. The band areas represent $68 \%$ error bands. 